Review

\title{
Polymer-Based Microfluidic Devices for Pharmacy, Biology and Tissue Engineering
}

Ahmed Alrifaiy ${ }^{1,2}$, Olof A. Lindahl ${ }^{1,2,3}$ and Kerstin Ramser ${ }^{1,2, *}$

1 Department of Computer Science, Electrical and Space Engineering, Luleå University of Technology, SE-971 87 Luleå, Sweden; E-Mails: ahmed.alrifaiy@ltu.se (A.A.); olof.lindahl@1tu.se (O.A.L.)

2 CMTF, Centre for Biomedical Engineering and Physics, Luleå University of Technology, SE-971 87 Luleå, Sweden

3 Department of Radiation Sciences, Biomedical Engineering, Umeå University, SE-901 87 Umeå, Sweden

* Author to whom correspondence should be addressed; E-Mail: kerstin.ramser@1tu.se; Tel.: +46-920-491-648; Fax: +46-920-493-111.

Received: 2 March 2012; in revised form: 4 May 2012 / Accepted: 18 June 2012 /

Published: 3 July 2012

\begin{abstract}
This paper reviews microfluidic technologies with emphasis on applications in the fields of pharmacy, biology, and tissue engineering. Design and fabrication of microfluidic systems are discussed with respect to specific biological concerns, such as biocompatibility and cell viability. Recent applications and developments on genetic analysis, cell culture, cell manipulation, biosensors, pathogen detection systems, diagnostic devices, high-throughput screening and biomaterial synthesis for tissue engineering are presented. The pros and cons of materials like polydimethylsiloxane (PDMS), polymethylmethacrylate (PMMA), polystyrene (PS), polycarbonate (PC), cyclic olefin copolymer (COC), glass, and silicon are discussed in terms of biocompatibility and fabrication aspects. Microfluidic devices are widely used in life sciences. Here, commercialization and research trends of microfluidics as new, easy to use, and cost-effective measurement tools at the cell/tissue level are critically reviewed.
\end{abstract}

Keywords: microfluidics; tissue engineering; biomedical engineering; polymers; biocompatibility; cell sorting; cell analysis; cell biology 


\section{Abbreviations:}

AC

ATP

$\mathrm{CNC}$

$\mathrm{COC}$

DC

DEP

DNA

ECM

E. coli

EDEP

EOF

hMSCs

HTC

IC

MACS

$\mu \mathrm{TAS}$

PC

PCR

PDMS

$\mathrm{pH}$

PMMA

PMT

PS

Re

RNA

SPRI

$\mathrm{Tg}$

UV

UV-Vis

UVLIGA
Alternating current

Adenosine tri-phosphate

Computer numerical control

Cyclic olefin copolymer

Direct current

Dielectrophoresis

Deoxyribonucleic acid

Extracellular matrix coating

Escherichia coli

Electrodeless dielectrophoresis

Electro-osmotic flow

Human primary mesenchymal stem cells

High throughput screening

Integrated circuit

Magnetically actuated cell sorter

Micro total analysis system

Polycarbonate

Polymerase chain reaction

Polydimethylsiloxane

Measure of the acidity or alkalinity of an aqueous solution

Polymethylmethacrylate

Photomultiplier tube

Polystyrene

Reynolds number

Ribonucleic acid

Solid-phase reversible immobilization

Glass transition temperature

Ultraviolet

Ultraviolet-Visible

Ultraviolet lithography, electroforming and molding

VSCEL
Vertical cavity surface emitting lasers 


\section{Introduction}

The field of microfluidics [1] was pioneered 40 years ago by the development of devices for silicon-based gas chromatography and microfluidic-based nozzles for ink jet printers [2,3]. It was not before 1990 that the first device with integrated microfluidic structures was developed for chemical analysis [4]. Thereafter, a remarkable increase of microfluidic applications appeared. Microfluidics, also called lab-on-chips or micro total analysis systems ( $\mu \mathrm{TAS}$ ), have become a hot subject in the life sciences [5], which has resulted in a huge number of published papers and reviews.

A major advantage of microfluidics is the ability to scale down systems to micro-sized chips [4]. This is associated with automation of manufacturing via different microfabrication techniques, a wide variety of different materials used for the chips, lower cost, and low demands for power and reagents. Further developments in microfluidics include novel polymeric materials, which complement the original silicon and glass-based microfluidic devices that initially came out of the electronics industry [6-10]. Nowadays, advanced microfabrication techniques enable the creation of complex, integrated microfluidic chips, which perform multiple analytic investigations on the same chip. Since the new techniques became available they have been incorporated into microfluidics. Many reviews on microfluidics have been published since the invention of the laser [11,12], especially in the fields of analysis in biology and chemistry [13-15], medical diagnostic assays [16,17], clinical analysis, forensic science [18], molecular diagnostics, genetic testing and DNA analysis [19,20].

In cell biology, the integrated "Lab-on-a-chip" has shown potential for analysis of intracellular reactions in single cells, at the sub-molecular level, and in tissue engineering experiments. The advantages are the exceptional properties of miniaturization, integration and automation. The systems allow new prospects for spatial and temporal control in investigations such as cell sorting, cell transport, immobilization and manipulation of biological systems in vitro, precise control of the microenvironment, cell culture, differentiation and many other applications.

Furthermore, combining microfluidic systems with different readout techniques have proven to be powerful tools in various applications, especially with great impact on the ongoing revolution in cell biology and biotechnology, as presented in this review.

In this review, we will focus on microfluidic characterization, fabrication, and the main applications related to biomedical engineering, pharmacy and cell/tissue biology. The intent is to present recent and current advances in microfluidic systems including applications, characterization and fabrication methods. The aim is also to emphasize the advantages of miniaturization for biological analysis and to present various cell biological applications. Different approaches in microfluidic systems are reviewed, including fluid and cell transport, properties of the involved materials, and a critical review of their advantages and disadvantages. Finally, we present a critical discussion about the different methods used, and present a brief overview about the recent developments and commercialization in the field of microfluidics.

\section{Microfluidic Systems, Flow Dynamics on the Small Scale, and Manufacturing}

This field deals with complete sequences of reliable design methods, fabrications and applications of micro-scaled channel systems connected by reservoirs or sealed inlets and outlets. The potential benefits are to produce portable microfluidic systems to improve life sciences as well as medical 
technologies and to perform large and complex cell-based biological investigations. In biomedical engineering, portable microfluidic systems could be used as diagnostic tools for rapid analysis of blood samples and other body fluids.

\subsection{Characterization of the Fluid Flow}

The behavior of the fluid flow within a microfluidic system differs from that in a macroscopic system. The micro scale dimensions of the channels allow for effects that are usually impossible in macro-scaled systems. These include surface effects, e.g., intermolecular forces that may change the viscosity. For instance, the surface effects are found to be lower when the height of the channels is decreased from 40 microns to about 10 microns [21]. Another important effect is the improvement of convective and radiative heat transfer due to the increase of surface-to-volume ratio [21].

In most microfluidic applications, it is important to understand and optimize the flow within two regimes, laminar or turbulent flow. Laminar flow (so-called streamline flow) occurs when the fluid flows in smooth and regular pathways, while fluidic parameters such as velocity and pressure are time-independent at each point within the fluid. The convective mass transfer of the fluid follows the direction of the flow under steady state boundary conditions [22]. To characterize the fluid behaviors within microfluidic channels the dimensionless Reynolds number ( $\mathrm{Re}$ ) is considered in most applications. The Re number quantitatively estimates the tendency of a fluid to develop turbulence, and it is defined as the ratio between the inertial and viscous forces on the fluid [23]. The parameters involved are the kinematic fluid viscosity, the actual fluid velocity and the characteristic diameter of the channel represented by the volume-to-area ratio of the channel [24].

Laminar flow is achieved by using small microfluidic channels with lower fluid velocity and relatively high viscosity. The laminar blood flow through the capillaries of the human body has been examined to explain this phenomenon [25]. Since the characteristic diameter of microfluidic channels is small, typically $<500 \mu \mathrm{m}$, the Re number can be lower than 10, and the fluid flow is expressed as laminar. The liquids are transported in uniform layers of thickness, between fixed boundaries, where mixing of the streamed liquids occurs by diffusion across the liquid-liquid interfaces [26].

\subsection{The Fluid Transport}

For most microfluidic systems, optimization of the fluid transport within the channels is necessary. Experimentally, the flow can be generated from high volume rates for cytometric applications [27,28] to low rates of $\mathrm{pl} / \mathrm{s}$ in applications demanding nano- and micro-scaled channels [29]. In some applications the fluid transport can be controlled by the fluid mass transport due to diffusion [30]. This can be explained by the thermal energy when particles spread in the fluid due to Brownian motion. The main methods in fluid transport are pressure-driven flow [31], electro-kinetic flow [32] and fluid transport created by motor proteins [33].

\subsubsection{Pressure-Driven Flow}

This common method uses either embedded micro-pumps within the microfluidic chip [34], or external pump systems to generate external pressure flow, such as positive displacement pumping [35], or ultra-precise syringe pump systems [36]. The advantage is the ability to control the exact amount 
and location of the pumped fluid. The limitations are difficulties to achieve smooth fluid flows at very low rates within small channels and the non-uniform velocity profile of the flow [37] as shown in Figure 1A.

Figure 1. The fluid flow profile within the microfluidic channels. (A) Pseudo-parabolic profile in pressure-driven flow; (B) Uniform velocity profile in electro-osmotic driven flow.

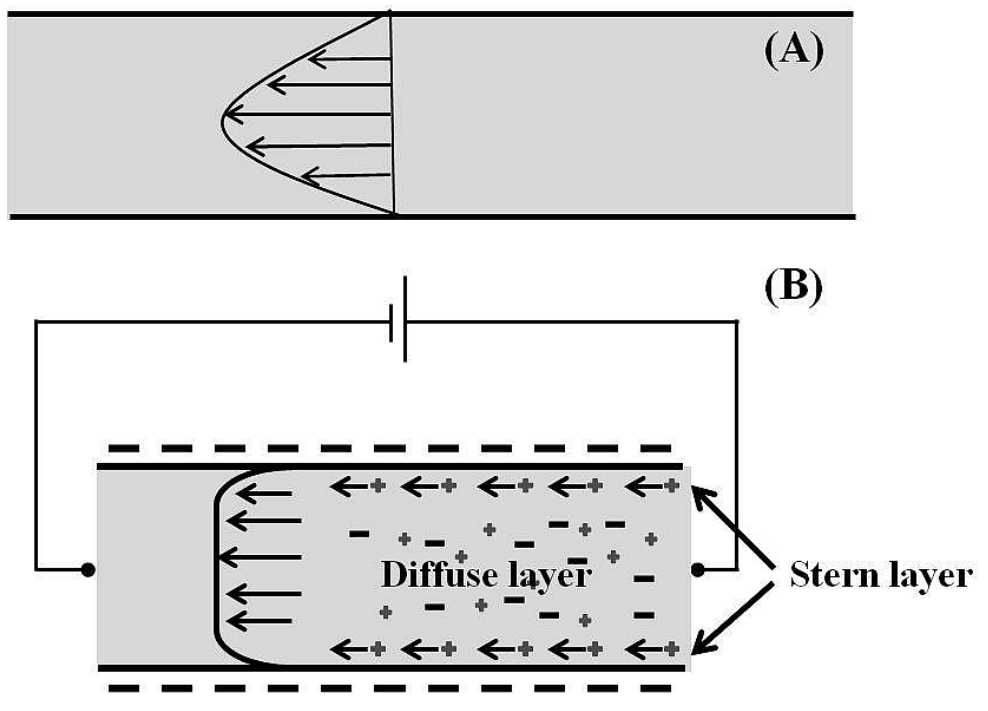

The pseudo-parabolic profile shows that the maximal velocity of the fluid is in the center of the channel, and the flow decreases to zero at the walls. The phenomenon can be investigated by software simulations using Navier Stokes equations with proper boundary conditions [38].

In some applications, the control of the fluid transport is achieved by using external pump systems. The pump systems are chosen depending on the quantities to be transported, the behavior of the transported fluid, and the pump system's influence on the measurements.

\subsubsection{Electro-Kinetic Flow}

Electro-kinetic transport within microfluidic channel is based on the movement of charged molecules in an electric field. This is performed either by capillary electrophoresis (CE) transport of charged samples relative to stationary fluid, electro-osmosis (EOF) transport of ionized fluids relative to stationary charged surfaces or by combining both techniques, as described below.

\subsubsection{Electro-Osmotic Flow (EOF)}

The fluid transport is generated through microfluidic channel walls of chargeable materials. An electric field is induced when a thin ion-layer of liquid is formed at the wall surface which is oppositely charged to the charge of the wall [31]. The fluid will operate as an electric double layer; a thin layer (Stern layer) of counter ions at the wall and another thicker layer (diffuse layer) of excess charges with the same polarity as those in the Stern layer. The ions within the Stern layer are fixed at the wall and the ions in the diffusion layer are movable.

By applying an electric field across the channel the fluid will move towards the electrode of opposite polarity, starting near the walls and transferring via viscous forces to the convective motion of 
the fluid. Experimentally, an open channel at the electrodes produces a uniform velocity profile while a closed channel causes a recirculation pattern in which the fluid along the center of the channel moves in a direction opposite to that at the walls, as seen in Figure 1B [32].

Since the flow is dependent on the interaction between the micro channel walls and the driving fluid, a higher efficiency of fluid flow is obtained when the micro channels are less than $100 \mu \mathrm{m}$ in diameter [33]. This method has been used with different microfluidic devices fabricated from different materials such as glass [35], polymers [36,37] and PDMS (polydimethylsiloxane) [38]. The method is used widely in capillary electrophoresis [39]. However, this method is not qualified for some electrophysiological investigations due to the noise arising from electromagnetic fields [40].

\subsubsection{Electrophoresis Flow}

Electrophoresis flow results from the accelerating force due to the charge of a molecule in an electric field balanced by the frictional force [39]. The induced forces accelerate the charged ions towards the cathode and the anode. The movement velocity of the ions in an applied electric field is expressed by electrophoretic mobility $\mu=\mathrm{v} / \mathrm{E}$ where $\mathrm{v}$ is the movement velocity of ions and $\mathrm{E}$ is the electric field intensity. Hence the mobility is independent of particle size (for uniform surface charge and electrical field). One approach is to manipulate samples within an ionic buffer solution at a specific $\mathrm{pH}$. The samples, cells or particles, will experience a different mobility that may be separated depending on their size and charge (Figure 2B). However, depending on the channel construction and the used substrate material, a bulk electroosmotic flow component may overlay on the electrophoretic movement of the sample, due to charges induced on the surfaces. Thus, the precise control of surface charge and buffer $\mathrm{pH}$ is essential to achieve best possible separation of samples. Another approach is to introduce a polymer gel into the separation channel, which is commonly used for separation of DNA and proteins [41]. The polymer gel creates size dependent electrophoretic movement. The smaller molecules experience less resistance (Figure 2C).

Figure 2. Electrophoresis approaches within microfluidic systems. (A) Sample movement in free solution; (B) Electrofocusing; (C) Gel electrophoresis.

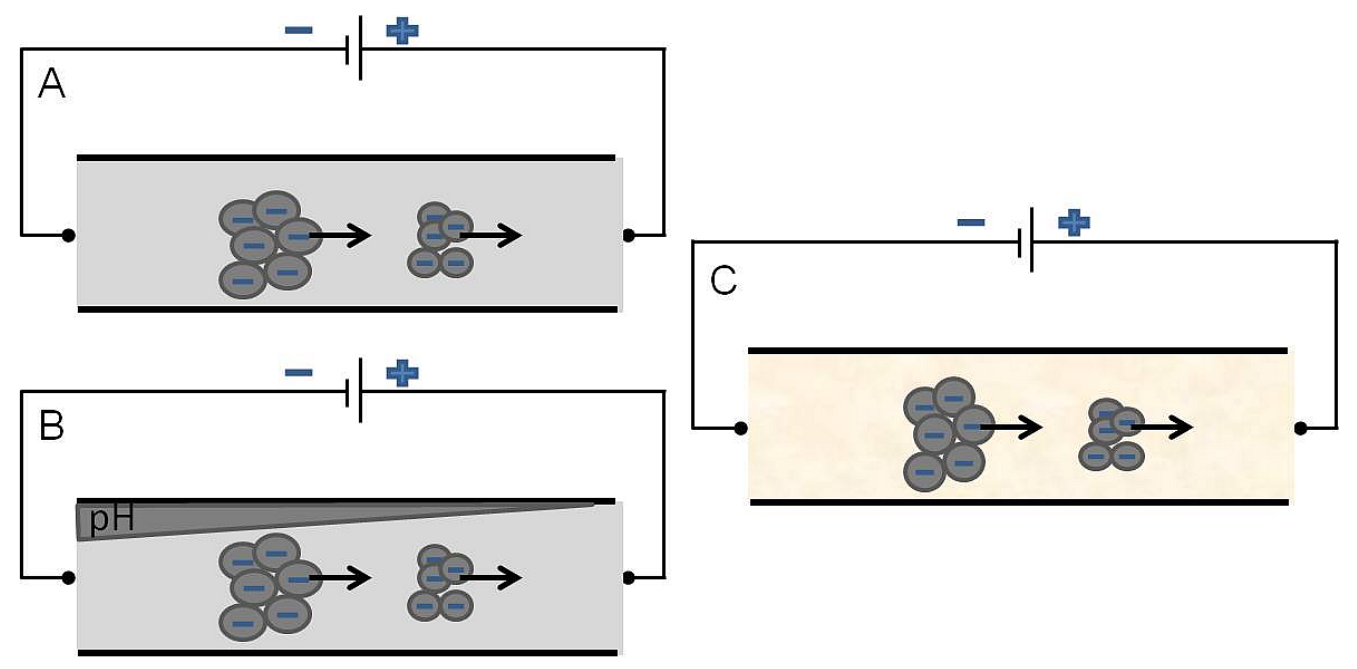


Gel electrophoresis diminishes the diffusion expansion of the separated zones within the microchannels and the electroosmotic flow due to the adsorption of the gel matrix that create neutralized surface charges on the microchannel walls.

\section{Fabrication of Microfluidic Devices}

Microfluidic devices were initially based on non-polymeric materials like silicon or glass, fabricated by the well-established integrated circuit (IC) production techniques such as photolithography and surface micro-matching due to the equipment availability and the possibility to be integrated with electronics. Glass materials were preferred for their excellent biocompatibility [42-46] and the high tolerance of high temperature and strong solvents [47] that was suitable for application with capillary electrophoresis. However, the drawbacks were mainly the non-optical transparency of silicon, the high cost and the micromachining complexity of silicon and glass materials.

The present research and commercialization have shown advantages with fabrication techniques that are based completely on polymer/plastic materials [48].

The popularity of such alternative materials is mainly based on the low cost, disposability, durability, optical transparency, biocompatibility, simple component-integration (such as interconnections, tubing and fittings), design-flexibility for wide ranges of applications, and chemical or mechanical properties. Latterly, glass, silicon or polymer have been used individually or combined with other material to produce microfluidic systems [2,49-61].

The reduction of fabrication costs and the optimization time have been improved by rapid prototyping techniques, where device geometries are quickly evaluated [62].

State-of-the-art fabrication techniques of microfluidic devices may be classified into direct techniques such as laser ablation or laser micromachining of polymers [63], photolithography or optical lithography [64], X-ray lithography [65] and prototyping techniques, including hot embossing [66,67], injection molding [68,69], and soft lithography [9].

\subsection{Integrated Micromachined Devices}

Micromachined devices have shown new advances to control the fluid flow within microfluidic systems, allowing high levels of microchip integration and analytical throughput. Many designs in various applications have been presented over the past ten years. They show a considerable potential for integrated microfluidic devices or systems, including microvalves, micropumps, and micromixers, as described below.

Embedded microvalves improve the function of microfluidic systems by controlling the direction of fluid flow over time. Micropumps for control and manipulation of fluid volumes on-chip are good options to replace external pumps [70].

Microvalves are used to control the fluid flow within the microchannels by changing external parameters. The activation of the valves may be performed mechanically via external pressure that physically alters the PDMS wall [48,71-73], pneumatically by using flexible membrane-based valves $[49,56,74-80]$, or using valves that function as switchers for continuous flow between channels using electroosmotic flow techniques [81-84]. The flow can be modulated by microvalves based on phase-modification of different materials such as paraffin [77,78,85], aqueous solutions [86], or 
hydrogels $[87,88]$. External forces can be applied on single-use valves so that flow is induced or impaired at a critical time point, such as by removing flow resistance [89-91] or by breaking apart a portion of a membrane [92-94].

Micropumps are used to control the fluid flow in microfluidic systems that can be classified as passive or active devices. The passive devices within microfluidic systems allow the fluid to move spontaneously close to surfaces. They are based on the surface tension of the fluid and the walls of the channels. A promising commercial design for a capillary pump based on this phenomenon has been presented [95]. The limitations associated with the surface tension boundary at the end of the microchannel may be avoided by the surface tension of droplets placed at inlets and outlets of microchannels to drive the flow. The benefits of surface tension-based micropumps are low cost and simple performance, but the time variation of the flow rates makes it unfeasible for automatic flow control [96]. Passive micromixers based on pumping energy are shown in various configurations, such as T-, or Y-shaped, parallel lamination, sequential, focusing enhanced mixers, and droplet micromixers.

The active micropumps operate in different manners using external pumping activities to initiate, control and stop the fluid flow. The advantages are the temporal control of the flow rate and the opportunity to enhance and control more complicated on-chip fluidic functions. The generation of external energy sources for mixing can be performed by using pressure-driven, electro-kinetic, dielectrophoretic, electrowetting, magneto-hydrodynamic, and ultrasound techniques. Most of the well established micro-mixers are based on pressure-driven flows [97].

\subsection{Direct Fabrication Techniques}

\subsubsection{Photolithography}

Photolithography is a technique based on the exposure of light on a photoactive material that undergoes a chemical reaction to form a liquid-solid transition. The basic components needed for photolithographic fabrication are a light source, usually UV light of 254-365 nm, a spin coater with programmable speed and time, and a suitable substrate with a photo-reactive material [98].

As shown in Figure 3, a non polymeric solid substrate (glass or silicon) is spin-coated to apply a thin layer $1-500 \mu \mathrm{m}$ of photoresist, usually SU-8, by centrifugal force. After evaporation of the solvents in the photoresist via soft baking, the substrate is exposed to UV light through a high-resolution mask of plastic or glass film with the desired microfluidic pattern. After baking, depending on which photoresist is used, the un-, or exposed layer of the photoresist is removed using chemical bath development. The desired pattern remains on the substrate forming a positive or negative mold. The light-exposed areas on the positive photoresist are usually soluble. For the negative photoresist, the areas are insoluble. The photoresist is often used to obtain negative molds for PDMS-based microfluidic devices replicated by soft lithography [64].

The advantages of photolithography are mainly the spatial control of light and the high resolution of the microstructured fluidic devices or molds produced. However, some limitations have been reported: lower sealing quality, chemical invariability of the surface, absence of other materials and related photoresists that can be used instead of traditional silicon [99]. 
Figure 3. Photolithography to fabricate microfluidic devices. (A) A photoresist is spin-coated on a silicon substrate; (B) The substrate with the spin-coated layer of photoresist is exposed to UV light through a high-resolution mask; (C) After baking and chemical development, the non-cross-linked material is removed, resulting in either a negative or a positive mold.

A

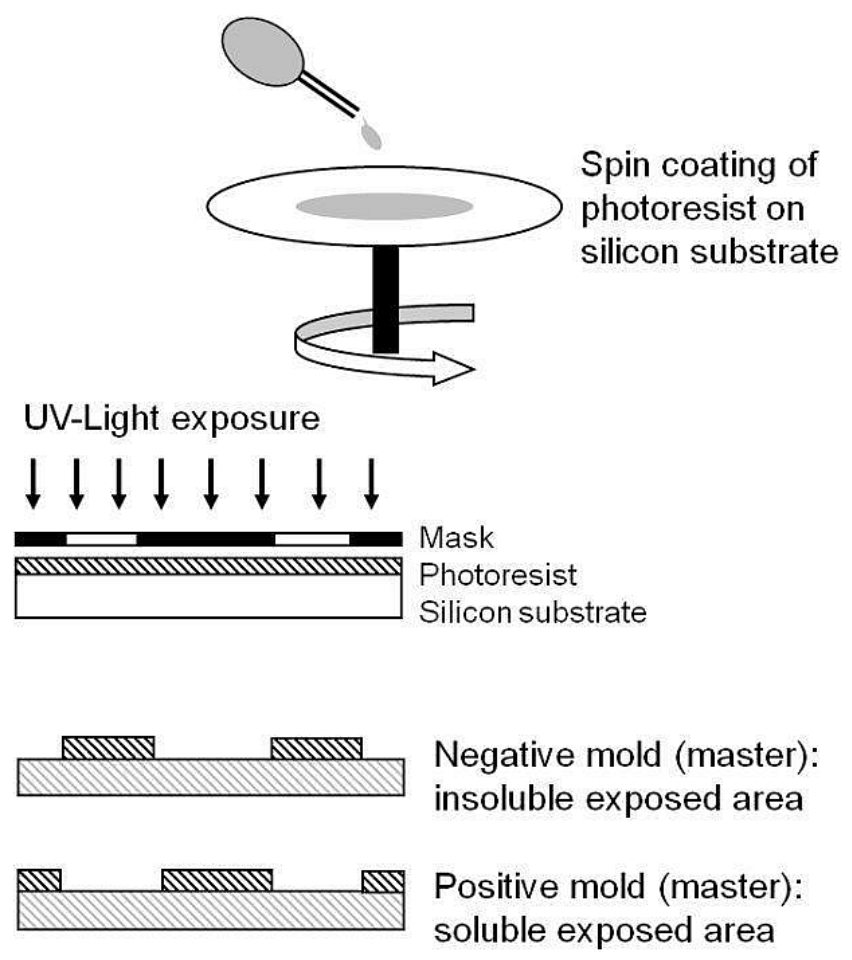

\subsubsection{The Conventional Surface Micromachining}

The Conventional Surface Micromachining technique is based on non polymeric materials, such as silicon and glass, to create high precision 3-D microstructures. A layer of protective organic material is spin-coated on a substrate followed by prebaking and photolithography to produce organic patterns on the surface of the substrate. After removal of the non-crosslinked material, the surface is etched and the material in unprotected portions is removed. Micromachining of silicone substrates is well established to yield precise devices with surface modification techniques, such as plasma deposition [100]. Furthermore, mass production of identical devices is easily realized due to the high automation level for surface micromachining. The disadvantages of surface micromachining are the long production time, high cost, fragility, invariability of the material, and the inability to obtain deep etched channels [101]. Several silicon-based micromachining methods, such as wet and dry etching and other methods have been reviewed [102].

\subsubsection{Laser Ablation Micromachining}

Laser ablation micromachining is based on the energy of laser pulses to break bonds in a polymeric molecule and to remove the decomposed polymeric fragments from the ablation region. This enables the creation of polymer-based microfluidic structures $[103,104]$. The depth and width of the channels are adjusted by the laser intensity and repetition of the beam exposure along the same channel. 
Depending on the energy per laser pulse and the material of the used substrate, the ablation rates per pulse are about $0.1-5 \mu \mathrm{m}[103,104]$. Ranges of polymeric material have been used with this method, including PMMA, PS, PC (PET) [105,106]. Bonding of PMMA-based microstructured devices can be achieved by using solvent-assisted gluing, melting, laminating and surface activation. The advantages are the short cycle time of production. The disadvantage is mainly the high cost of manufacturing [107].

\subsection{Prototyping Techniques}

\subsubsection{The Hot Embossing Technique}

The Hot Embossing technique is based on a mold of permanent microstructures that is bossed gradually by pressing with a specific force on a polymeric thermoplastic substrate while it is heated slightly above the glass transition temperature (Tg) of the substrate [108]. After cooling, the thermoplastic substrate is released, and contains a glassy or semi crystalline microstructure. The method enables straightforward fabrication of microfluidic devices of single layers and thin channels. However, to produce devices with enclosed channels, bonding of multi thermoplastic layers with heat, glue or other techniques are necessary [109].

The advantages are mainly the ability to fabricate nano- and micro-structures [110] and to use molds for the replication of many devices without degradation [111]. The challenge is to shorten production times per device with faster thermal cycling. Thus, mass scale fabrication of thick devices is more cost efficient. Also, the shallow channels make it challenging to achieve connections within the microchip. Moreover, undercut structures cannot be shaped; therefore assembly of separately fabricated layers is essential for enclosed structures.

Recently, a broad range of improvements has been reported, related to hot embossing techniques. Large-scale hot embossing to create low cost and high quality microfluidic structures has been presented [112]. Using simulation-based modifications, it is possible to improve the demolding forces and to reduce damage, such as shrinkage and warpage of microstructures during demolding. In contrast to standard hot embossing of simple surface structuring, PMMA-based double sided hot embossed structures were linked through holes to the fluidic structure by double-sided aligned mold inserts [113].

Based on functional titer plate-based microfluidic platforms, a 96-well solid-phase reversible immobilization reactor system (SPRI) was replicated [114]. The large area patterned mold inserts were fabricated using an SU-8 based UVLIGA (Ultraviolet Lithography, Electroforming and Molding) lithographic technique with high precision. Leak-free sealing was achieved by thermal fusion bonding of the molded chips. This work was extended to a high throughput, multi-well (96) polymerase chain reaction (PCR) platform, based on a continuous flow (CF) mode using double-sided hot embossing [115]. The hot embossing system combined with a servo pneumatic system during a rapid thermal cycling to form force feedback was achieved due to the low thermal mass in the forming area [116].

A novel infrared (IR)-assisted roll-to-roll embossing method of two micropatterned metallic rollers was developed for replication of microfeatures onto flexible polymer substrates. IR radiation energy 
was used to produce thermal heating to melt the polymer substrates during hot embossing and replicating the microstructures [117].

\subsubsection{Microinjection Molding}

With similar procedures as used for the commercial macro-scale injection molding, a thermoplastic polymer is liquidized by heating and injecting under high pressure into a high precision mold cavity. The mold is rapidly cooled below the Tg of the polymer and the finished device is ejected. The benefits are the rapid mass production, the geometrical quality, and the multi-level structures with different depths. The challenges are to reduce the cost of the high quality molds and to assemble separate layers for the construction of closed microfluidic devices [118]. Mass replication of polymeric microstructures using a conventional injection molding process with mold inserts of wet-etched silicon wafers have been optimized [118].

Another approach is to improve the injection molding process with high temperature and rapid thermal response to enhance the quality of plastic injection without increasing the total cycle time [119].

Mass replications of plastic microfluidic chips with interconnecting ports and holes were fabricated by a microinjection molding process using mold cores with pin structures [120].

\subsubsection{Computer Numerical Control (CNC) Micromachining}

Computer numerical control (CNC) micromachining [121] is used for fabrication of PMMA-based microchips. Most analytical microchips require features with dimensions in the order of 10-200 $\mu \mathrm{m}$. Such tolerances are possible with CNC milling as a standard fabrication technique. The conventional CNC milling is used to fabricate prototype microchips for straight use or structured molds of harder materials for rapid generation of analytical microchip platforms via PDMS casting or hot embossing. In some applications, the CNC machines may be combined with microscopic surveillance to yield microchips with accurate tolerances on milled structures in the order of $2-10 \mu \mathrm{m}$ [122].

Prior to any milling, drilling, or cutting, the desired tolerances of the vertical and horizontal positions of the mill should be adjusted relative to the surface of the block of PMMA or other materials. For accurate aspect ratio features, the depth of the feature, the $z$-axis, is pre-calibrated. The size and shape of the desired micro channels are achieved by using cutter drills with different tips related to the desired features. To achieve the best tolerances, test modules are pre-fabricated and investigated under commercial microscopes to monitor the desired sizes and features.

The advantages of this method are low cost of material, the ease to create milled designs quickly, and the availability of CNC machines at universities or at commercial workshops. The disadvantages are the poor surface quality, low yield strength, substrate hardness, and poor tolerances [121]. In addition, the inability to assemble the tolerances required for analytical microchips with features $<10 \mu \mathrm{m}$ is one of the most significant limiting factors of CNC milling for lab-on-a-chip devices.

Many studies have reviewed experimental and modeling aspects of micromachining processes, specifically micro milling [123-125]. Micro factories, micro-, and ultra-precision machine tools have been designed and developed for micromachining applications [123,124]. Numerical and analytical modeling of different aspects of micro milling has been investigated extensively [125]. 
Microchip electrophoresis devices based on PMMA were fabricated by hot embossing from mold masters fabricated rapidly via high-precision micromilling. Numerical simulations were used to determine the effects on injection plugs (i.e., shape, size, concentration profiles) due to the curvature of the corners. The sidewalls of the polymer microstructures were characterized by a maximum average roughness of $115 \mathrm{~nm}$ and mean peak height of $290 \mathrm{~nm}$. PMMA microchip electrophoresis devices were used for the separation of double-stranded DNA. The plate numbers achieved in the micromilled chips exceeded $1 \mathrm{million} / \mathrm{m}$, compared to the plate numbers obtained for the LIGA-prepared devices of similar geometry [126].

\subsubsection{Soft Lithography}

Microfluidic devices of polymeric thermoset microstructures of PDMS are formed by molding against a negative image of the desired structure [39,127]. Usually they are fabricated by photolithography using silicon or glass, depending on the desired resolution and the number of replications that the mold must withstand. A typical production process is schematically described in Figure 4. The resulting devices have many attractive properties, such as chemical inertness and facile bonding to glass or other layers of PDMS, i.e., multiple layers which enable efficient fluid flow pumping schemes [40].

Figure 4. Replication of PDMS based microfluidic devices produced by soft lithography. (A) The needles are located in connection with the channels prior to pouring PDMS into the mold; (B) The needles are removed, and the finished microfluidic system is released from the mold after thermal curing; (C) The microfluidic system is placed on a cover glass.

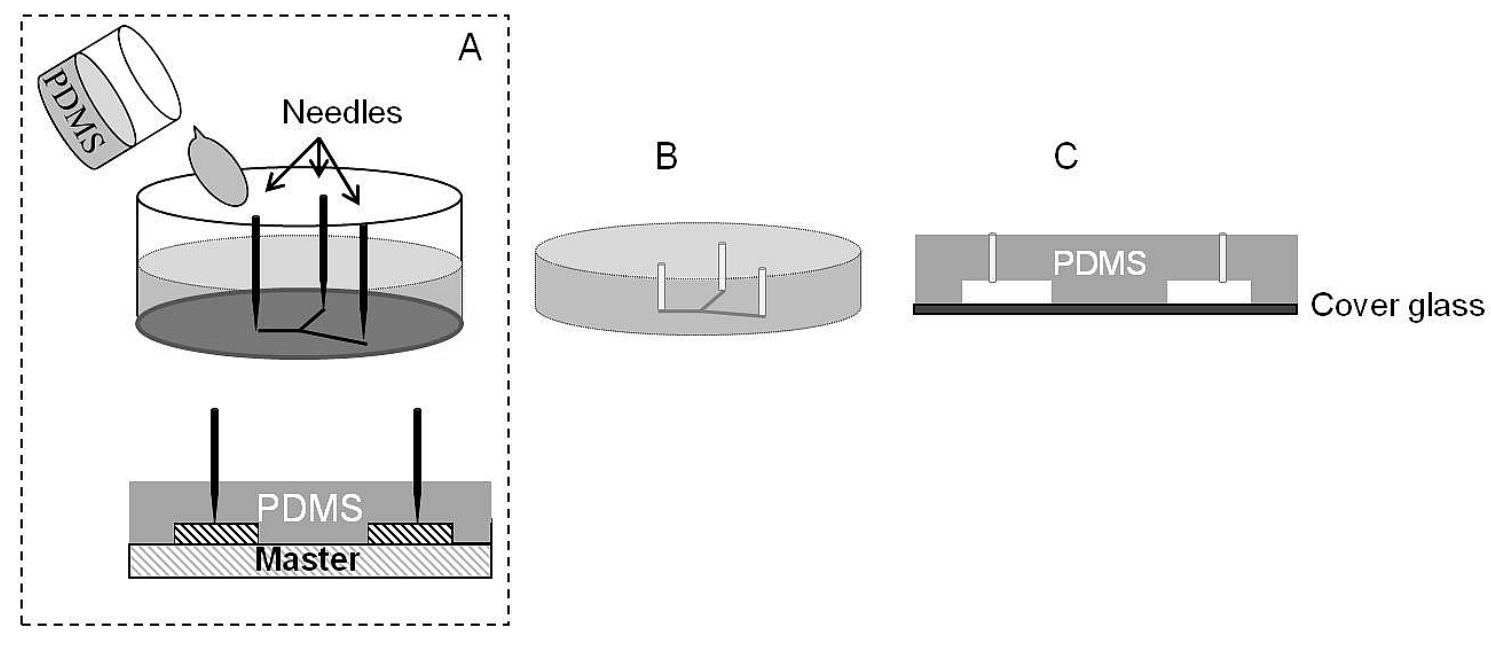

The surfaces can be modified compared to other materials to achieve hydrophobic to hydrophilic transformations through oxygen plasma treatment. However, plasma-treated surfaces will maintain the hydrophilicity for only short laboratory experiments and device verification. The limitation of the quick hydrophobic recovery of PDMS surfaces has been addressed either by attaching larger molecules to the surface for increased durability of the surface or by network forming modification to increase the surface stability [40].

The main disadvantages of soft lithography are the invariability, and that they are incompatible with non-polar solvents that may block the channels or cause cross contamination of adjacent fluid streams. 
Furthermore, PDMS is usually thermally cured and patterned through material exclusion against a negative-image mold. The connections, such as channels and reservoirs within the layer, are often manually fabricated with needles placed before pouring the PDMS, as seen in Figure 4, or by hole-punching in the finished microfluidic device, which may reduce the precision and repeatability.

\subsection{Bonding: Complementary Step for Fabrication of Microfluidic Devices}

Bonding of polymer substrates is a challenging and critical issue in fabrication of functional microfluidic devices. The general methods of bonding are mainly the thermal compression at higher temperature up to Tg. Bonding by chemical modification of substrate surfaces using plasma treatments $\left(\mathrm{UV} / \mathrm{O}_{3}\right)$ are traditional methods for bonding of PDMS. Alternatively, adhesive bonding by gluing (e.g., UV curable materials) or using curable epoxies can be used [128].

\section{Microfluidic Applications in Pharmaceutical, Biological and Biomedical Engineering}

\subsection{Manipulation of Biological Cells on-Chip}

During the last few years, the manipulation of biological cells in microfluidic devices has increased widely in biology, medicine and biotechnology. The manipulation of biological cells makes it possible to move the sample without coming into physical contact within a closed microfluidic system. Most touch-free manipulation techniques can be easily integrated into existing setups, making them widely usable. The main methods are presented in the following sections, with some detailed descriptions on the common applications in cell biology.

\subsubsection{Magnetic Manipulation}

Magnetic manipulation is a contact-free method and uses magnetic forces induced by external or embedded magnetic fields [129] to manipulate magnetically labeled biological cells. The cells are labeled magnetically by attaching nano-paramagnetic beads with high selectivity. The magnetic beads can be functionalized with antibodies, peptides or lectins to interact with the biological cells [130]. Typically, the diameter of the chosen magnetic beads is about $10-100 \mathrm{~nm}$ to guarantee minimum damage to cellular function or cell viability [131].

Designs of various microfluidic cell sorters have been presented using embedded ferromagnetic wires [131], micro-electromagnetic matrix [132] or plastic-coated steel wool to avoid cell damage [133]. The method has been applied to control the efficient manipulation and treatment of red blood cells [134]. Another approach improved the trapping efficiency of relatively rare cells in blood samples by magnetically trapped beads within open tubular capture beds [135]. Escherichia coli (E-coli) bacteria can be magnetically separated from solutions and blood by a mixer within the microchannels [136]. Other designs of microfluidic chips with integrated micro magnetic stripes and super-paramagnetic nanoparticles for cell separation have been reported [137]. A microfluidic device with parallel magnetic lines along the flow chamber to capture, guide, and move the magnetic-labeled cells [131,135-137] and local magnetic fields created by an orthogonal array of electrical wires [133] have been demonstrated successfully. The advantages are the parallel sorting (multiple cells per time and location) and cost efficiency. The disadvantages are the low sensitivity and selectivity to trap rare 
cells [133], the long-time and sensitive procedures for magnetic labeling and releasing of the beads. Commercialization of the technique has been presented as a Magnetically Actuated Cell Sorter (MACS) by Miltenyi Biotec GmbH, in Germany [138].

In other designs, a quadrupole magnet surrounding the flowing cellular solution enables the deflection of magnetic-labeled cells in desired directions [139]. A magnetic cell sorter based on free-flow magnetophoresis is used to separate cells based on variable receptivity of magnetic material between different cell populations [140]. These methods show drawbacks mainly due to cell adhesion, low throughput, and low recovery due to the number of beads attached to the cells [135].

Magnetic separation of label-free blood cells based on their local magnetic properties has been presented [141]. Using a constant magnetic field to separate cells based on the inherent magnetism of each cell in a population was demonstrated by magnetophoresis of red blood cells and labeled human lymphocytes $[142,143]$. Red blood cells that are diamagnetic were separated from white blood cells that are paramagnetic or diamagnetic [144]. The method is hygienic, flexible, non-invasive, and may be adapted within various microfluidic systems for a variety of cell manipulation applications.

In contrast to the optical and electric field manipulation techniques, the magnetic field is basically permeable to biological tissues and cells, and it is not expected to interfere with cell function. It has also been shown that the magnetic particles do not influence viability or function of the labeled cells $[122,131]$. One principle of magnetic sorting can be seen in Figure 5.

Figure 5. Schematic of DNA stretching by attaching a magnetic bead to one end of the DNA molecule while the other end is fixed onto the surface of the cover glass.

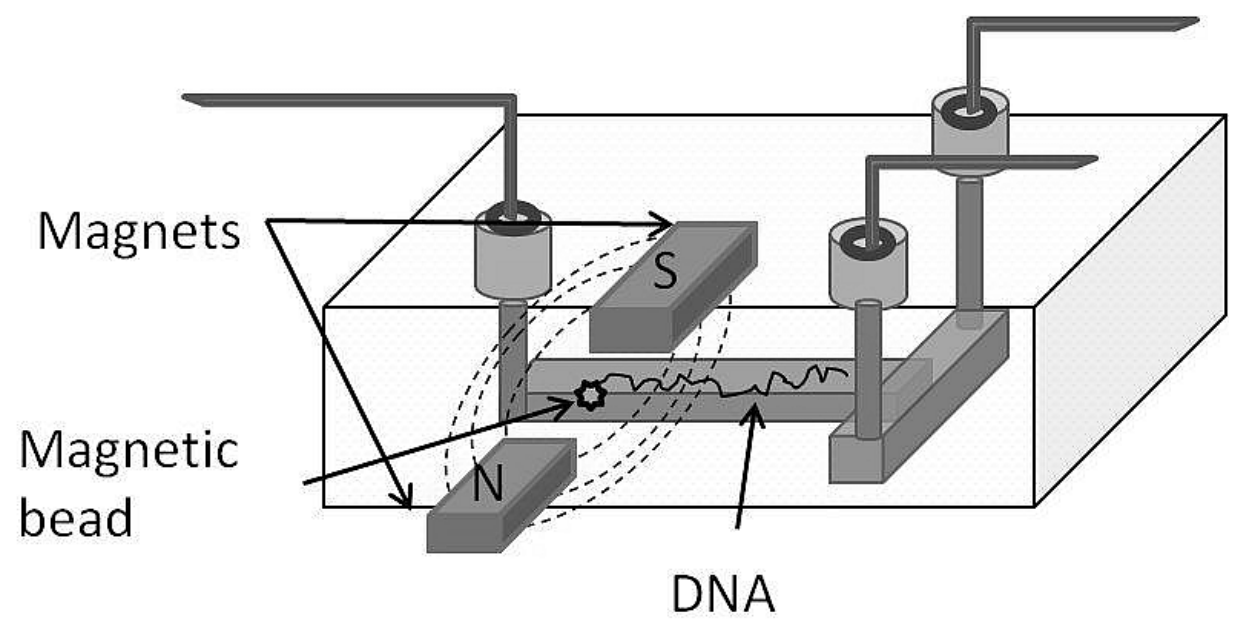

The drawbacks are mainly the weak aligning force, which can be improved by a high presence of molecules within the sample, and the high magnetic susceptibility [145].

Additionally, manipulation of individual magnetic beads requires more complicated control over the external magnetic fields. Furthermore, the efforts to optimize magnetophoretic conditions for manipulation of biological samples are still insufficient for broad applications [146]. 


\subsubsection{Mechanical Manipulation}

The mechanical manipulation of biological cells on chips is challenging due to the physical conditions. To understand the physical behavior of cells, structure-function interactions require knowledge from biological, biophysical, and biochemical fields. Cell mechanics and physics describe the way that biological cells are moved, deformed, sensed, generated, and how they interact and respond to mechanical forces [147-150].

Cell analysis and separation are the major application of on-chip mechanical manipulation. Microfluidic devices with structures such as micro-filters [147-150] have shown poor selectivity and are hence limited for cell-based applications. Micro-well structures [151-153] such as micro-grippers are used for single cell manipulation without damage to the cells but are complicated to produce [154]. By using etched dam structures along the microfluidic channels in the fluid flow direction it is possible to allow biological cells to be moved, docked and aligned in desired locations $[38,155]$. In other microfluidic designs with similar functionality, etched structures of multi-shape and height grooves on master-slabs are positively replicated onto the PDMS to create protruding features with different heights, called "sandbag" structures [156]. The techniques require simple fabrications procedures and offer the potential to control cell transport, to immobilize cells, and to dilute analyte solutions to generate a concentration gradient with minimal stress. Hence, this technique may be useful for upcoming applications in microfluidic cell analysis. Some approaches involve reactive-coating of the inner surface of the microfluidic channels [157-159] with antibodies [160,161], with selectin (cell adhesion molecules) [162] or with enzymes [163]. These coating techniques use cell adhesion to enable trapping of cells with fairly low immobilization.

Arrays of rectangular mechanical filters within microfluidic channels have been used for trapping various types of cells found in blood [127,164,165]. In another design, hydrodynamic forces have been used to move and filter the blood cells through a pattern of channels [164,165]. A limited volume surrounded by vertical silicon slabs has been used as a microreactor volume to trap particles [166]. Micro-patterned filters can be used to separate white blood cells from blood, where genomic DNA targets can be directly amplified by PCR on the filtered cells [40]. Size-based microfilters have been reviewed including Weir filters, Pillar filters, Cross-flow filters combined with continuous flow (CF) and membrane filters for mechanical separations of blood cells and DNA molecules [167,168]. The efficiency of microfilters and the simplicity to be integrated within microfluidic systems has been evaluated [167,168].

The sticky tendency and transient tethering of cells has been used as a biomimetical method for cell separation based on micro-structured channels [162]. Another approach using micropipettes to seek cells and draw them out of an optical trap is an interesting tool to manipulate individual cells [169]. The technique is based on microfluidic channels designed with integrated pipettes in custom-made holes. First, a buffer with beads flows into the channel where single beads are optically trapped, moved and held on the circular-shaped top of the integrated pipette. Then a solution of DNA molecules flows through the channel until one molecule sticks to a single trapped bead. Continuous flowing enables a second bead to be connected to the DNA molecule. Thereafter, the stretching experiments on an assembly of DNA molecules have to be performed separately [169]. 


\subsubsection{Electric Manipulation}

The ease to create and structure a micro-scale electric field on a microchip has been shown to be an alternative method to manipulate biological cells in various applications. The advantages are speed, flexible control and automation. The applied electric fields, depending on the nature of the experiments, are DC fields for electrophoresis of charged particles, AC non-uniform fields for dielectrophoresis (DEP) of polarizable (charged or neutral) particles and AC combined with DC for manipulation of charged and neutral particles. Electrophoresis is described as the motion of dispersed particles relative to a fluid flow generated by a spatial and uniform electric field [170]. The technique is used in combination with electro-osmosis fluid flow for the electrokinetic transport and separation of cells in microchannels [42,171-173]. Due to the similar electrophoretic motilities of most biological cells, the applications of electrophoresis for manipulation are limited and almost exclusively used for pumping (electroosmotic flow, EOF).

Dielectrophoresis (DEP) [174,175] is based on non-uniform electric fields that induce polarization of uncharged particles that experience lateral motion. A DEP trap is usually produced by an electric field gradient with an array of planar metallic electrodes connected to a power supply, or free-floating in the presence of an AC field [176]. DEP enables the parallel electrical manipulation of micro- and nano-biological cells, DNA, proteins and nanoparticles. An improvement was achieved by electrodeless DEP (EDEP), which allows the application of a high electric field without gas development and allows an increase of the dielectric response at low frequencies $(<1 \mathrm{kHz})[139]$. DEP has been reported successfully in applications on microfluidic devices to separate and manipulate a variety of biological cells such as bacteria, yeast and mammalian cells [177-192].

\subsubsection{Acoustic Manipulation}

Acoustic manipulation of biological cells uses radiation forces formed by interactions from ultrasonic gradient fields that generate acoustic scattering from the cells. The principle of acoustic manipulation is shown in Figure 6.

Figure 6. Schematic view of a device for particle size sorting. Suspended particles from a solvent such as blood cells from plasma are sorted using two parallel transducers close to the main channel to produce a field of the ultrasonic standing wave. The particles in the solution, affected by the ultrasonic standing waves, are directed to one side of the channel while the diluted solution flows via the central channel to the outlet.

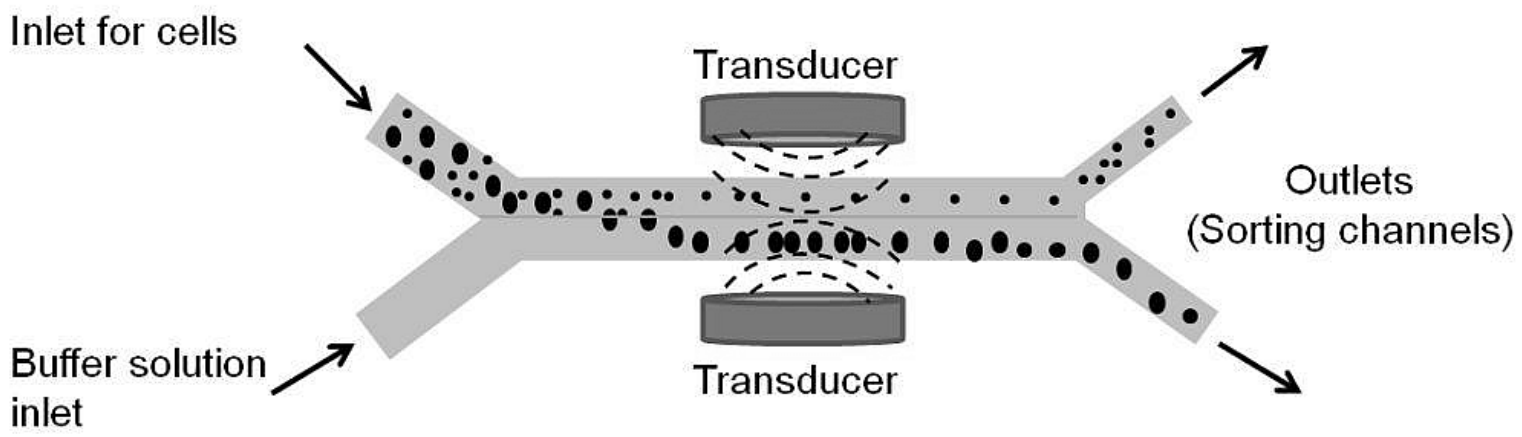


Acoustic manipulation can be combined with microfluidic systems. The acoustic manipulation generates potential wells of ultrasound that are relatively high, which lowers the accuracy of spatial 3-D manipulation of individual cells. Ultrasonic forces may allow manipulation of cells without damaging their viability by using low-power ultrasound waves [193]. The method is usually used as a complement to other manipulation techniques such as optical, dielectrophoretic (DEP), and magnetic trapping.

Acoustic based microchips of multilayer resonant configurations have been designed for cell culturing experiments [194]. The application area for acoustic trapping is mainly to study cell cultures in perfusion systems and related properties, such as non-adherence behavior. This allows for a controlled cell microenvironment, and it is possible to design systems for in vitro studies of cell or microorganism behavior and proliferation. One important issue with ultrasonic trapping is cell viability. Studies have shown that acoustic trapping of biological cells does not affect the viability of the cells [194-196]. Acoustic trapping has been used to culture yeast cells [195], study the effect on inherent agglomeration for in vitro cell-cell interaction studies such as cell adhesion dynamics [196-198], long-term culturing [199], and investigation of cell viability and proliferation such as for Hep2G cultures in alginate-gel [200]. Successful acoustical trapping of microparticles has been shown in a flow chamber under environmental control, while Raman spectroscopy was used to detect, distinguish and monitor the chemical reactions in real time [201].

\subsubsection{Optical Manipulation}

The combination of microfluidic systems with optical techniques has shown great potential to manipulate and investigate single biological cells optically in various applications such as cell trapping, sorting and analysis without contact or contamination.

Optical tweezers [202] are well known trapping techniques that use the radiation of laser light to induce forces acting on dielectric particles such as biological cells in three dimensions. Experimentally, a stable optical trap is achieved by focusing a laser beam strongly through a high-numerical aperture (NA) microscope objective onto the sample. The trapped object is usually manipulated by moving the trap and/or the sample stage with high precision.

Successful results have been presented with optical tweezers combined with a microfluidic system, where single yeast cells are separated, positioned, immobilized, and then cultured successfully in a thermo-sensitive hydrogel within the microchannels [203]. The growth of the embedded cells was examined under a microscope and the viability of a specific single cell was confirmed in real time [204].

Using multi-microwell arrays of 25 to $30 \mu \mathrm{m}$ diameter on the bottom of $3 \mathrm{~mm}$ wide microfluidic channels, individual cells have been picked up from the wells using optical tweezers under microscopic visualization [204]. The cells were injected into the channels, sedimented into the wells, and inspected, while cells outside the microwell array and unneeded cells were removed optically. Trypan Blue exclusion was used to demonstrate cell viability and to maintain the sticky tendency of the cells at the bottoms of the microwells [204].

Optical tweezers have been used to stretch or tie bio-filaments such as DNA or actin by attaching and trapping beads in the ends of the filament using dual optical tweezers [205]. This was employed to 
investigate the elasticity of a DNA filament using a custom-designed laminar flow fluidic system with parallel flows and rapid exchange of buffers during the experiment [206].

The use of holographic tweezers or computer-controlled spatial light modulators makes it possible to trap, manipulate and investigate several biological objects simultaneously with a single laser under controlled environments [207].

Single bacterial cells in micro-cultivation have been isolated and placed in microchambers to study the reproducibility of genetically identical bacteria under varied environments through the microfluidic system [174]. High throughput was achieved by using vertical cavity surface emitting lasers (VCSEL), as multi-trapping and manipulation devices [208,209]. The limitation is the lower trapping strength [210]. Cell sorting was achieved in high efficiency by using optical polarizability of particles with an extended, three-dimensional optical lattice within the microfluidic system [211].

A portable microfluidic device combined with Raman spectroscopy has been presented. The method is based on chip-embedded waveguides in optical fibers to enable the detection of noise-free and fast acquisition of Raman spectra of analytes within the microfluidic chip [211].

Resonance Raman spectroscopy, optical tweezers and microfluidic systems have been combined to mimic in vivo conditions in an in vitro milieu. Globin-containing cells were investigated within a microfluidic system related to their sensitivity, photo-induced effects and uptake and release of oxygen [212].

A new concept of a multifunctional gas-tight microfluidic system combined with optical tweezers and optical spectroscopy for electrophysiological investigation of single biological cells has been presented [213]. A patch clamp micropipette was integrated at a fixed position within the microfluidic chip. A red blood cell (RBC) was trapped and optically steered until it became attached to the pipette tip, while different oxygenation states of the RBC, triggered by altering the oxygen content in the microchannels through a pump system, were optically monitored by a UV-Vis spectrometer [213].

\subsubsection{Flow Cytometry on Microfluidic Chip}

The commercial potential to sort cells rapidly and the possibility of mass-produced cell sorter devices became accessible in the early 1970s. The method is used to count and investigate biological cells moving within a fluid to be detected by electronic devices. The physical and chemical properties of huge numbers of biological objects per second are simultaneously multi-parametrically analyzed. The applications are found mainly in the diagnosis of health disorders, blood cancers, and purification of cell populations for both research and clinical areas.

Flow sorting allows individual, physical and chemical analyses of biological objects passing through a light source. A cell or particle of interest can be separated from a heterogeneous population after analytical identification by cytometry using a flow sorter. Historically, flow cytometry was based on a photoelectric apparatus for microscopic counting of individual biological cells flowing through micro tubes [214]. This was followed by using hydrodynamic forces to position the cells in the center of the fluid flow [215]. More demonstrations and improvements of the flow cytometer have been presented [216-219]. It is essential to offer important biological information about cell volume, DNA and proteins in many types of biological cells. Valuable reviews of cell sorting techniques have been reported [220-224]. 
Multi-parametric analysis by flow cytometry is a powerful tool to identify, separate and study specific individuals from a complex population. For example, the composite of observable characteristics of an organism could be identified by a specific antibody-antigen interaction including, e.g., measurements of DNA and RNA content [225] of cells, functional characteristics of ion flux and $\mathrm{pH}$ [226], and cell reactions such as apoptosis and cell death [227].

Under sterilized conditions, flow cytometric methods have been used to isolate specific cell populations for culturing [228]. Cell sorting can be used for functional assays [229] or for transplantation of animal tissues in the laboratory [230] or the study of human T-, and B-cells from patients [231], or for sperm sorting for subsequent insemination and sex selection [232]. Different types of organisms have been studied using flow sorters for yeast [233-235], bacteria [236], phytoplankton [237] and sub-cellular organelles such as the Golgi complex [238] or chromosomes [239]. Flow sorting has shown the benefit of isolating large numbers of specific chromosomes from humans during the human genome sequencing project, as well as for other primates [240], plant species [241], and more recently in the production of chromosome paints [242]. Flow sorters have also shown their advantages to sort specific subsets of cells for microarray analysis [243], to sort single particles into individual wells of a plate for cloning [244] and to perform polymerase chain reaction (PCR) analysis [245]. To enable cell transport or sorting on microfabricated chips [246], hydrodynamic [247,248] electro-kinetic [42], electro-osmotic [173,249] and DEP forces $[177,194]$ have been used.

Another approach has shown the possibility of performing magnetic and fluorescent-activated sorting using laminar flow switching in microfluidic devices. Magnetic particles have been sheathed with two buffer streams and separated from non-magnetic particles by the deflection in a magnetic field gradient. A photomultiplier tube (PTM) has been used to detect the fluorescently-labeled particles. The PMT switches a valve on one of the outlets of the sorter microstructure and selects a particle by forcing it to the collecting outlet [247].

Another microfluidic device was designed for cytometry of fluorescently labeled E. coli samples in surface coated channels to reduce cell adhesion. Focusing was performed electrophoretically without electroosmotic flow [42].

Parallel luminescent single cell assays on a microfluidic chip have been developed to sort populations of cells upon the dynamic functional responses to stimuli. A DEP-based regular array of single cell traps has been designed to confine and hold the cells against disrupting fluid [249].

Disposable sorting on microfluidic chips using an electrokinetic fluidic flow was demonstrated for effective sorting of micro-beads and bacterial cells with a high throughput of 20 cells/s [177]. However, the limitations with such an electrokinetic mechanism are incompatibilities and frequent changes of voltage settings, uneven pressure, evaporation, and that ion depletion occurs within the buffer.

In another cell sorter, switching valves, dampers and peristaltic pumps have been integrated into the channels to improve the throughput, buffer compatibility, automation and cell viability [250].

Based on microfluidic devices for centered cell analysis and sorting [177,251], high centered cell sorters have been developed [252,253]. In one design, single cells are suspended and floated without restraint in microfluidic channels along a focal plane of an electromagnetic field created by a 3-D electrode pattern. Stable trapping of single cells in dielectric fields in the flowing medium is 
performed, while spectroscopic and microscopic measurements are acquired. The trapped cells are assessed and analyzed based on their fluorescent properties. This combination of 3-D electromagnetic field with high-resolution fluorescence enabled the cells to be loaded with a supplementary agent, i.e., calcein [252].

In another interesting approach, impedance spectroscopy has been used for cell sorting. Two different frequencies of the real part of the impedance are used to effectively differentiate erythrocytes from ghost cells with a transit time of one millisecond [254].

Cell counting with a prototype of a Coulter counter has been presented. The flow of non-conductive liquid surrounds the sample liquid and changes the ratio of the flow rates of the two liquids to adapt to the diameter of the Coulter aperture [255].

A micro-cytometry system for human pathogen exposure to monitor leukocyte populations has been presented [256]. A flow cytometric detection device on-chip has been demonstrated as a novel approach, based on a laser-induced fluorescence detection system, combining solid state laser detection with microfluidic technology [257].

\subsubsection{Cell Analysis}

Microfluidic-based devices for cell analysis give the benefits of reduced cell consumption, reduced reagent consumption, and easy reproducibility. Analytical systems have been used for controlled cell transport and immobilization, and for dilution of an analyte solution to generate a concentration gradient. The microchips allow the measurement of cellular processes while the cells are exposed to a concentration gradient of the test solution and real time monitoring is performed [38].

Along with the ongoing progress in the field of gene manipulation, cloning, in vitro fertilization, handling and manipulation of individual livestock embryos on-chip, pre-implantation of individual mouse embryos have been tested and transported through a system of channels to selected locations [258]. The selection and mobility of sperm have been studied using antibodies that are attached within the microchannels [259].

Cell shapes related to growth, gene expression, extracellular matrix metabolism, and differentiation have been studied by cytometric and chemical analysis of the visco-elastic behavior of the red blood cell membrane while the cells were flowing in microfluidic channels [260].

Chambers for mammalian cell culturing can be based on topographically-patterned capillaries. Cells are cultured inside capillaries that have flat surfaces. The cells spread equally in all directions [261]. The attachment of cells on smooth surfaces has been studied on astroglial cells of different shapes and sizes of silicon material while techniques such as reflectance, fluorescence, confocal light microscopes and scanning electron microscopy have been used to quantify the cell attachment [262].

In another approach, laminar flow in a microfluidic system has been used to induce steady shear stresses on adherent cells to study cell adhesion on biological substrates [263]. PDMS-based microfluidic capillary systems have been used to study the growth of E. coli bacteria in real time on chips using fluorescence microscopy [264].

Due to the excellent permeability of PDMS to oxygen and carbon dioxide, microfluidic channels have been used as culture vessels for ovary cells that are examined visually [265]. Cell stimulation and observation of the immediate cell responses in vivo have been studied using a microfluidic system with 
a scanning thermal lens microscope detection system and a cell culture microchip [266]. The detection of non-fluorescent biological cells with high sensitivity was achieved.

Cell-based biosensors have shown their advantages for sample preparation, control of the biological environment, and electronic device integration for data analysis. The development of the system with an integrated silicon-PDMS cell cartridge, including digitalized interface, temperature control, microelectrode electrophysiology sensors, and analog signal buffering, have been described [267].

A system to provide both cell culturing, and impede- and potentio-metric characterization on a chip has been developed [268,269]. A similar system of microchannels for culturing, stimulation and neural cell recording has been presented where the fluidic channels are used for local and fast delivery of drugs to the cells [270].

A chip-based patch clamp is used to understand the role of ion channels in a single cell in human physiology and to develop therapeutic assays [271]. To date, electrophysiological measurements such as a patch clamp are accurate enough to provide detailed information about the ion channels, but the method is still slow and too complicated to be automated. The goal of a microfluidic-based patch clamp is to replace conventional patch electrodes with a planar array of miniaturized recording boundaries on either a silicon, polymer or glass substrate. Such devices have been shown to enable real-time electrophoretic self-positioning of charged lipid cell membranes over micro-sized holes [272]. It was possible to obtain stable gigaohm seals for electrophysiological investigations of the cells. The devices could potentially be mass-fabricated with defined geometry and material properties by standard silicon technology to perform multiple recordings on a single chip. A demonstration of patch clamping in a microfluidic device was performed by 3-D silicon oxide micro-nozzles in which the cells were positioned by applying negative pressure through the hollow nozzle [273]. In another approach, an electrophysiological-based multifunctional microfluidic system with an integrated multi-electrode structure has been shown to perform whole-cell patch clamp and general extracellular stimulation, and the recordings were combined with impedance spectroscopy [274].

Chip-based fluorescence microfluidic systems can be used for the detection of membrane potentials of individual cells [275]. In this study, the pseudo-ratiometric transform in fluorescence was examined upon membrane depolarization or hyperpolarization. Cells within the microfluidic channels were detected after mixing with compound solutions which enabled higher throughput. The influence of microchannels on neurite growth and architecture has been investigated [276].

Nowadays, the commercialization of the microfluidic-based patch clamp solutions for ion channel analysis are sold by companies such as Sophion Biosciences (Ballerup, Denmark), Molecular Devises (Sunnyvale, CA, USA) that have incorporated Axon Instruments and Cytion, AVIVA Biosciences (San Diego, CA, USA).

\subsubsection{Cell Culturing}

Traditional culturing experiments in cell biology are performed by macroscopic culturing methods using ECM-coated Petri dishes. Microfluidic systems offer the opportunity to scale down the systems to the cellular level [264], which can improve the in vivo conditions of the cell culture. The micro scaling of devices essential for various biological applications enables control over factors related to 
growth concentration, chemical and mechanical stimuli, and the downscaling forms a locally stable cell microenvironment for cell cultures [277]. Compared to traditional culture methods, microfluidic systems offer possibilities for multi channels or chambers, control of cell colony mutation, multifunction processing of medium exchange and substrate patterning, integration of stimuli and measurement element (e.g., mechanical, electrical) [278,279].

Microfluidic systems for cell culturing are mainly fabricated with silicon, PDMS, and borosilicate. The materials have been tested on embryo cultures and have shown great potential for in vitro production of mammalian embryos within microfluidic systems [280]. Another study has shown that microfluidic bioreactors are efficient for perfusion culture of fetal human hepatocytes (FHHs), which is promising for future liver tissue engineering [281].

Microfluidic devices for bacterial culture have been presented with integrated chemostat and medium regeneration for long-term colony culturing under controlled conditions [282,283]. Cell culture arrays have been developed with integrated gradient generators to monitor fluorescence gene expression in several independent bacterial colonies with different environments [284]. The viability of cells was enhanced for several weeks by using arrays of multi chambers with independent culture environments [285].

Combining hydrogel with PDMS into a hybrid device imitates the 3-D cellular environment [286], which has been successfully applied to produce 3-D-ECM matrixes of aligned fibers for endothelial cell cultures [287].

Microfluidic system devices have been shown to regulate topographical features in PDMS and multiple laminar flows of etching fluids in capillaries [261]. In another design, a PDMS-based microfluidic system for cell culturing has been designed. Channels with high aspect ratios were included within arrays of microfluidic chambers, and these channels allow continuous perfusion of solutions. The system offers possibilities to localize the cells inside the microfluidic chamber and enable cell growth in a homogeneous microenvironment [288]. Many other microfluidic devices for enhanced cell growth, culturing and micro-environmental changes with various perfusion systems have been reported [289-295].

New designs of 3-D-structured microfluidic systems for cell culturing have been presented [296-298]. Some use alternative biocompatible materials [299,300]. A novel method of fabrication of non-contact 3-D photo-thermal etching uses infrared focused lasers with wavelengths of $1480 \mathrm{~nm}$ [296] and 1064 $\mathrm{nm}[301]$ to create micro-structured agar for cell cultivation.

Droplets at a channel junction were applied to generate high parallelized fluid segments. The concept was demonstrated for cell cultivation to manipulate cells within the channel junctions [301]. By integrating a microelectrode array within the microfluidic channels for cell culturing, the electrophysiological activity of cells could be recorded [302].

One approach to study single cells within a cell culture in a microfluidic system is to monitor individual cells without noise due to population heterogeneity of the culture [303]. A commonly used method is to pattern adhesive patches on the substrate, and for less adherent cells, individual hydrodynamic traps can be combined with continuous flow [304] and fast media switching [305] for single-cell experiments. One application using those methods applied a microfluidic device for automatic positioning of individual single Hela cells [306], and trap arrays were designed for interaction assays between two different cell types [307]. 


\subsubsection{Cell-Based High Throughput Screening (HTC)}

HTS devices enable large-scale screening of huge amounts of chemical compounds that are compared to specific molecules in the compound chemical library in a relatively short time [308-313].

Traditionally, biological cell-based assays are performed using titer multi-well plates to enable handling of the large library of chemical compounds. However, miniaturizing the titer plates to micro scale volumes offers opportunities for robust, precise and rapid methods, which save time and cost [308-310]. For this reason, various microfluidic systems have been developed for continuous high screening assays by designing single chips that enable both manipulation and analysis of compounds [311]. Microfluidic technology offers the potential for miniaturization and therefore parallelization of experiments [312]. For example, microenvironments can be controlled in high-throughput screening by miniaturized microfluidic cell culturing systems. A high-throughput microfluidic platform for high parallelized protein interaction measurements capable of detecting transient interactions has been designed. A chip with thousands of individually-programmed reaction chambers using microarrays integrated within the microfluidic system has been presented [312]. Cells are loaded precisely, based on the control of the cell density. Each chamber is fed with complex mixtures of components, while optical readouts of each chamber are highly automated. The study investigated the differentiation of human primary mesenchymal stem cells (hMSCs) with various seeding densities and duration of stimulation. It was shown that the complex culturing conditions were difficult to achieve using classical high-throughput culturing methods with multi-well plates. The design of higher parallelization systems with these multiple cell reaction chambers in single cell measurements with high temporal and spatial resolution provides more knowledge about cellular responses to these micro-environments [312]. One approach is 3-D chips with microfluidic valves, a system of 16 independently addressable cell culture chambers in one array that are loaded with hydrogels and stem cells [313].

Micro-beads composed of hydrogels, cells and test compounds have been produced in microfluidic systems with a stop-and-flow lithographic method or via microfluidic droplet generation [314,315].

Hydrogel microbeads formed as crosslinked microdroplets include liquid gel in the presence of cells [314,316-320]; these have been fabricated from a rapidly-polymerized and dense alginate [318-321]. These approaches have strong potential to be used in biosensors, cell sensors, drug delivery systems, and cell transplantation applications, such as the encapsulation of cells in alginate hydrogels with a high monodispersity. This demands extensive incubation channels for gradual polymerization and soft hydrogel systems [322]. This microbead method has shown that the growth of some types of stem cells is weak in such cross-linked hydrogel systems.

One approach has been to design a droplet-based microfluidic system that allows for the generation of thousands of uniform droplets speedily, and each single droplet can function as a nanoscaled titer plate. It is based on the injection of solutions into a stream of a carrier fluid such as oil within the chip, and hence, due to the non miscibility of the oil and the liquid, they meet and emulsify reproducibly at a very high frequency [323]. This valuable idea has been implemented for various operation mechanisms [309,310,324-326]. This technique has shown to be convenient for cellular drug analysis with high throughput by gathering biological cells in self-assembling configurations [327-329]. 
Microfluidic systems have been widely used for the patterning, culturing and stimulation of cells, together with high-throughput cellular investigations in a single device [330]. Microfluidic systems have also been shown to offer precise control over the cellular microenvironment due to precise fluid handling [331]. One presented approach is a single chip where enzymatic assays in picoliter-scale droplets are used to perform high-throughput drug screening [332-334].

\subsubsection{Tissue Engineering Models on Microfluidic Chips}

The topic of tissue engineering includes mainly in vitro reconstruction of tissue or organ function. Microfluidic systems may offer opportunities to facilitate such applications. Lately, a generation of artificial lung tissue has been produced on a microfluidic chip with an immunological functional bi-layer of endothelial and epithelial cells on two sides of a porous PDMS membrane [335]. The system has been used as a model to investigate the toxicity of nanoparticles [336] by imitating the deformation of the bi-layer that activates the dependent uptake of nanoparticles by the epithelium.

3-D tissue models, such as bone marrow, use advanced biomaterials that can be photo-polymerized by microfabrication techniques such as photolithography, to create complex patterned structures [337-339]. Microfluidics can also allow precise configuration for micro-tissues on chip models [340] or 3-D micro-tissues off chip using hydrogel microbeads [341]. The challenge to create functional artificial tissues is the 3-D patterning of manifold types of cells into a tissue-like structural design. The control of components of 3-D co-culture spatial systems by microfluidics is valuable [342-344]. An approach using a hydrogel bi-layer of hepatocytes and endothelial cells has allowed the imitation of interstitial flow for the formation of tissue-like structures by the hepatocytes [345].

\subsection{Biocompatibility and Cell Viability within Microfluidic Systems}

The most important topics in biological cell applications within microfluidic systems are biocompatibility and cell viability [346]. The investigations of adhesive properties of biological cells on chip have shown that there are no negative influences on the cellular conditions and behavior [347]. Other studies have shown that PDMS-based microfluidic systems can maintain normal cell viability for several weeks [348-351]. The biocompatibility of microfluidic systems based on other materials such as silicon oxide, PDMS and glass were investigated, and all showed good cell viability [347].

Another important issue is to design and fabricate a microfluidic system to ensure delivery and diffusion of gases such as carbon dioxide and oxygen. For glass-based systems, the delivery is performed usually by gas dissolution within the liquid, while for PDMS-based systems, the gas-permeability through the PDMS surfaces is sufficient. Furthermore, the cell viability within a PDMS-based chip was investigated by varying the thickness of the material from a few micrometers to a few millimeters. This study showed no observable effects on cell viability $[352,353]$.

Another important topic is to investigate the shear stress on biological cells. Depending on the type of the investigated cell, the shear stress should be monitored and/or controlled under cell culture conditions [354,355]. One example is to design microfluidic channels with flexible dimensions to easily change flow stress if necessary. 
In addition to the fluid flows, applying external fields within microfluidic systems, such as for cell manipulation, should be considered and related to cell viability. Studies have shown that cell sorting by dielectrophoresis [185] and optical trapping [356] does not disturb the physiological conditions of the cells if great care is taken. This is especially important when applying optical tweezers. Many studies deal with the photoinduced effects caused by the trapping lasers, and for each new application, viability studies should be performed [357]. Acoustic methods for cell manipulation within microfluidic systems, such as using ultrasound, have been reported to be without significant effects on cell viability [358].

Studies have shown good viability of living cells when grown on cellular microenvironmental chips [359-370]. Microfluidics replaces the parallel plate chambers for cell growth, and shear stress investigations establish the need to match the length scales between the fluidic channels and the cells [359-370].

Microfluidic systems can offer minimum hemodynamic shear stresses on biological cells. One application has used a design in which a two-phase microfluidic system mimics the physiological and pathophysiological effects associated with pulmonary airways [371].

In another study, microfluidic systems have been used as in vitro models for investigation of the role of blood cells in hematological diseases [372,373]. Microfluidic channels have been used to study the deformability of red blood cells infected with the malaria parasite Plasmodium falciparum. Viable cells could pass through the narrow channels while the infected, mechanically rigid cells could $\operatorname{not}[372,373]$.

\section{Discussion}

Microfluidic devices meet the challenge to enable physical conditions to control the behavior of fluids in micro-scaled domains in ways not previously available. Different fabrication techniques of microfluidic systems made from suitable materials related to specific applications have prospects to gain great impact in the fields of cell biology, pharmacology and tissue engineering.

For instance, the biocompatibility of the materials for various cell-based microfluidic applications has been studied widely. While microfluidic devices made in glass or silicon are still frequently used, the microstructuring of polymer-based microfluidic devices has found increased applicability in life sciences. Polymers have shown as good alternatives since they show high biocompatibility with many biological molecules and living cells [29,374-378]. The advantages of the intrinsic properties of PDMS are its biocompatibility [379], gas-permeability (oxygen and carbon dioxide) [380], low cost, optical transparency (240-1100 nm) with low auto-fluorescence, and submicron resolution molding [381]. PDMS can bond to glass cover slips by simple plasma treatment to form sealed channels. The deformability of PDMS enables fluidic leaks which are valuable for the creation of fluidic micro valves. PDMS may be oxidized to enable electro osmotic flows, and therefore the PDMS has the possibility to integrate micro-machines such as switchers within the chip. Furthermore, non-brittle PDMS-based microfluidic systems are physically robust. However, one drawback of using PDMS is the hydrophobicity of the polymer which complicates the investigation of drug metabolism and toxicity, since hydrophobic substrates can interact with the material [382-384]. To overcome this adsorption problem, a number of PDMS surface treatments have been developed. Due to the porous 
structure of PDMS, coatings with a hydrophilic compound can be performed [383,385]. However, the coatings might influence cell responses [386]. Furthermore, PDMS is permeable to water vapor, leading to evaporation inside the device, causing changes in the medium concentrations, or drying over time [40]. The formation of bubbles is a serious limitation for microfluidic systems fabricated from hydrophobic polymers where water has a tendency to rewet from the walls of the channels [387].

A large number of technologies and materials, such as silicon, PMMA, glass, parylene plastics, flexible polymers and gelatin [388], are currently available for the production of microfluidic devices [389]. Glass and silicon are expensive compared to the other materials, and flexible polymers share the disadvantage of PDMS of hydrophobicity. Materials such as gold, silicon nitride, silicon dioxide, silicon, and SU-8 photoresist have been identified as biocompatible [390]. However, silicon materials have shown unfeasible properties such as fragility and invariability.

Low cost thermoplastic polymers (plastics) have been used for micro fluidic devices in high quantities in industry. They allow for easy surface treatment and most of them are transparent and biocompatible. The surface of the plastics polymethylmethacrylate (PMMA), polystyrene (PS), polycarbonate (PC), and cyclic olefin copolymer (COC) can be oxidized with oxygen plasma or ultraviolet light to obtain high hydrophilicity. The effect of UV ozone treatment on the biocompatibility of polymers such as PDMS, PC, PS and COC has been shown to be feasible whereas long-term culturing on PMMA results in loss of viability [391]. Related to the nature of the experiment, a variety of materials can be used for producing microfluidic systems. For gas-tight microfluidic systems, it is valuable to use materials with lower gas-permeability, such as plastic materials.

The growing research in the field of microfluidics for cell-based studies has generated miniaturized devices for capillary electrophoresis, liquid chromatography, and PCR, and these devices achieve higher throughput chemical analyses using multilayer chip devices for the investigation of biochemical activity at the single-cell level.

An up-to-date review on polymer-based microfluidic systems offers a comparative overview of the materials used and their properties, such as advantages and disadvantages related to different microfluidic fabrication techniques and biological cell-based applications. The review offers an excellent outline of the main material used in microfluidic fields related to fabrication, well controllable cell-based investigations and the opportunity to integrate other micro-engineering applications [392].

In the field of drug discovery, small, highly automated, portable microfluidic diagnostic devices for bioassays have been shown to be optimal to replace traditional molecular diagnostic devices for DNA-based genomic or proteomic studies [393]. The ability to imitate the 3-D cellular environment on a microchip to study rapid cell-signaling actions, cell biology, and the response from exposure to stimuli or compounds at the tissue- or single-cell level could generate knowledge that so far has not been obtainable with existing assay strategies. For instance, mass-transport properties allow for high-throughput chemical analyses on the surface of chips with a throughput up to millions of assays per second. However, until now, the industrial production of instruments to perform microplate-based assays has not adapted to the novel microfluidic technologies developed in the academic arena. Hence, they are not yet expected to replace the traditional and well-established devices. As an example, microfluidics has greatly taken over the field of medical PCR, but PCR in industry is still based on 
more traditional and basic methods. In addition, the insufficient automation, relative complexity of the systems, and the challenges to integrate multiple functions on chips into a multifunctional microfluidic system is still the main limitation of a broader applicability of microfluidics in bioanalytics.

In the field of tissue engineering, the development of micro- and nanoscale tools to produce engineered tissue-organs and control cell behavior has widely increased during the last decade. This was possible due to the design of platforms for gradient microfluidics, microassay microfluidics, and cell microfluidics for high-throughput screening and micro-environmental control.

As an example, a variety of microfabrication techniques has been used to develop microscale devices in which cells, such as stem cells, could be manipulated to allow for the creation of bio-mimetic systems that imitate the natural cell environment or the pathological state of a tissue [394]. Another advance has been the introduction of multiple cell types into a microfluidic device to generate complex, miniaturized 3-D structures that mimic natural tissues or tissue structures composed of multiple cell types or miniaturized multi-organ systems. Growing different cell types in close proximity allows for cell-cell communication that can create a network to modify and regulate the microenvironment [395]. Another trend related to cell-based applications is to create 3-D artificial tissues suitable for transplantation. Whereas most fabrication technologies are based on 2-D methods, generating individual layers that can be stacked to create modular 3-D systems, emerging technologies, such as 3-D printing techniques, together can create 3-D microfluidic devices with precision down to the micron scale. One recent advance in microfluidics has been the development of alternative materials such as gel-like materials in which cells can be encapsulated and interact with each other, or degradable materials that can remodel cells [395].

As outlined in this review, the application for microfluidics and lab-on-chips are exponentially increasing and are here to stay. Recently, multifunctional microfluidic device companies have emerged in the market place. For instance, droplet digital PCR (ddPCR) genetic analysis platforms are offered by QuantaLife, disease diagnostic, detection, treatment monitoring, blood testing devices are offered by Sony, and microfluidic-based molecular imaging and detection devices for life science applications are offered by Caliper Life Sciences [396]. Cellectricon AB, have presented a Dynaflow ${ }^{\circledR}$ HT System, which enables fully automated high throughput electrophysiologic experiments [397]. Due to the increasing industrial interest and commercialization of microfluidic technologies, more efforts and investments should be encouraged to enable possibilities of mass-production of multifunctional microfluidic platforms. By analogy with the well-established standards of microelectronics in industry regarding mass production, it would be valuable to establish similar standards as a starting point for industrial growth of commercial multifunctional microfluidic systems. Microfluidic systems show a broad variety of size, geometry, layout, and material for many applications. Establishing microfluidic standards would allow for lower cost, greater automation, improved compatibility, and possibilities for minimized re-engineering [398]. This would certainly be a promising future task to perform.

\section{Conclusions}

We have reviewed microfluidics within the field of biology, pharmacy and tissue engineering. The devices are in most cases custom-designed and individually made with specific microfabrication techniques and materials to fulfill the requirements of each single application. The complexity of the 
systems can vary a lot; they can consist of only a few channels with inlets and outlets, or they can be equipped with complex micromachinery such as pumps and valves. Various microfabricated devices have been developed as fundamental tools to facilitate both advanced applications and basic research into the biology of cells and tissues.

In general, microfluidic systems for cell biology are essential for studies of the response of individual cells or cell cultures. From our point of view, in spite of the popularity of PDMS-based devices in many applications, rigid thermoplastic polymers such as PMMA can be the potential alternative for fabrication of microfluidic devices due to the low cost, optical transparency, ease of fabrication, high permeability to fluids, and biocompatibility. Additionally, thermoplastic-based microfluidic systems can be produced rapidly by a variety of high-throughput techniques such as CNC machining and hot or cold embossing.

In our opinion, the future of microfluidics lies in small, portable, cheap and exact devices for simple and fast diagnosis of diseases, testing of drugs or fast screening of blood samples for health evaluation. The review presented here shows many interesting and promising applications. However, the step to commercialization has not been realized yet. As mentioned above, a standardization of methods would probably be beneficial. Researchers would not have to develop custom made lab-on-a-chips for each application if readymade systems were easily available. This would boost the industrial development of microfluidics.

\section{References}

1. Gravesen, P.; Branebjerg, J.; Jensen, O.S. Microfluidics: A review. J. Micromech. Microeng. 1993, 3, 168-182.

2. Terry, S.C.; Jerman, J.H.; Angell, J.B. A gas chromatographic air analyzer fabricated on a silicon wafer. IEEE Trans. Electron Devices 1979, 26, 1880-1886.

3. Petersen, K.E. Fabrication of an integrated, planar silicon ink-jet structure. IEEE Trans. Electron Devices 1979, 26, 1918-1920.

4. Manz, A.; Graber, N.; Widmer, H.M. Miniaturized total chemical analysis systems: A novel concept for chemical sensing. Sens. Actuators B Chem. 1990, 1, 244-248.

5. Beebe, D.J.; Mensing, G.A.; Walker, G.M. Physics and applications of microfluidics in biology. Annu. Rev. Biomed. Eng. 2002, 4, 261-286.

6. Koch, M.; Evans, A.; Brunnschweiler, A. Microfluidic Technology and Applications; Research Studies Press: Baldock, UK, 2000.

7. Becker, H.; Locascio, L.E. Polymer microfluidic devices. Talanta 2002, 56, 267-287.

8. Stroock, A.D.; Whitesides, G.M. Components for integrated poly(dimethylsiloxane) microfluidic systems. Electrophoresis 2002, 23, 3461-3473.

9. Anderson, J.R.; Chiu, D.T.; Wu, H.; Schueller, O.J.A.; Whitesides, G.M. Fabrication of microfluidic systems in poly(dimethylsiloxane). Electrophoresis 2000, 21, 27-40.

10. Gast, F.U.; Fiehn, H. Profile. The development of integrated microfluidic systems at GeSiM. Lab Chip 2003, 3, 6N-10N.

11. Reyes, D.R.; Iossifidis, D.; Auroux, P.A.; Manz, A. Micro total analysis systems. 1. Introduction, theory, and technology. Anal. Chem. 2002, 74, 2623-2636. 
12. Auroux, P.A.; Iossifidis, D.; Reyes, D.R.; Manz, A. Micro total analysis systems. 2. Analytical standard operations and applications. Anal. Chem. 2002, 74, 2637-2652.

13. Pol, F.; Branebjerg, J. Micro Liquid-Handling Devices: A Review; MST: Berlin, Germany, 1990.

14. Jakeway, S.C.; de Mello, A.J.; Russell, E.L. Miniaturized total analysis systems for biological analysis. Fresenius J. Anal. Chem. 2000, 366, 525-539.

15. Chován, T.; Guttman, A. Microfabricated devices in biotechnology and biochemical processing. Trends Biotechnol. 2002, 20, 116-122.

16. Tüdős, A.J.; Besselink, G.A.J.; Schasfoort, R.B.M. Trends in miniaturized total analysis systems for point-of-care testing in clinical chemistry. Lab Chip 2001, 1, 83-95.

17. Vo-Dinh, T.; Cullum, B. Biosensors and biochips: Advances in biological and medical diagnostics. Fresenius J. Anal. Chem. 2000, 366, 540-551.

18. Verpoorte, E. Microfluidic chips for clinical and forensic analysis. Electrophoresis 2002, 23, $677-712$.

19. Huang, Y.; Mather, E.L.; Bell, J.L.; Madou, M. MEMS-based sample preparation for molecular diagnostics. Anal. Bioanal. Chem. 2002, 372, 49-65.

20. Erickson, D.; Li, D.; Krull, U.J. Modeling of DNA hybridization kinetics for spatially resolved biochips. Anal. Biochem. 2003, 317, 186-200.

21. Ho, C.M.; Tai, Y.C. Micro-Electro-Mechanical-Systems (MEMS) and fluid flows. Annu. Rev. Fluid Mech. 1998, 30, 579-612.

22. Currie, I.G. Fundamental Mechanics of Fluids; CRC Press: Boca Raton, FL, USA, 2002.

23. Kim, C.; Lee, K.; Kim, J.H.; Shin, K.S.; Lee, K.J.; Kim, T.S.; Kang, J.Y. A serial dilution microfluidic device using a ladder network generating logarithmic or linear concentrations. Lab Chip 2008, 8, 473-479.

24. Cardiovascular Physiology Concepts Homepage. Available online: http://www.cvphysiology. com/Hemodynamics/H006.htm (accessed on 28 February 2012).

25. Avila, K.; Moxey, D.; de Lozar, A.; Avila, M.; Barkley, D.; Hof, B. The onset of turbulence in pipe flow. Science 2011, 333, 192-196.

26. Kovarik, M.L.; Lai, H.H.; Xiong, J.C.; Allbritton, N.L. Sample transport and electrokinetic injection in a microchip device for chemical cytometry. Electrophoresis 2011, 32, 1-8.

27. Yang, R.; Feeback, D.L.; Wang, W. Microfabrication and test of a three-dimensional polymer hydro-focusing unit for flow cytometry applications. Sens. Actuators A Phys. 2005, 118, 259-267.

28. Weigl, B.H.; Yager, P. Microfluidic diffusion-based separation and detection. Science 1999, 283, 346-347.

29. Burns, M.A.; Johnson, B.N.; Brahmasandra, S.N.; Handique, K.; Webster, J.R.; Krishnan, M.; Sammarco, T.S.; Man, P.M.; Jones, D.; Heldsinger, D. An integrated nanoliter DNA analysis device. Science 1998, 282, 484-487.

30. Ocvirk, G.; Munroe, M.; Tang, T.; Oleschuk, R.; Westra, K.; Harrison, D.J. Electrokinetic control of fluid flow in native poly(dimethylsiloxane) capillary electrophoresis devices. Electrophoresis 2000, 21, 107-115.

31. Thompson, P.A.; Troian, S.M. A general boundary condition for liquid flow at solid surfaces. Nature 1997, 389, 360-362. 
32. Tallarek, U.; Rapp, E.; Scheenen, T.; Bayer, E.; van As, H. Electroosmotic and pressure-driven flow in open and packed capillaries: Velocity distributions and fluid dispersion. Anal. Chem. 2000, 72, 2292-2301.

33. Clemmens, J.; Hess, H.; Doot, R.; Matzke, C.M.; Bachand, G.D.; Vogel, V. Motor-protein "roundabouts": Microtubules moving on kinesin-coated tracks through engineered networks. Lab Chip 2004, 4, 83-86.

34. Laser, D.; Santiago, J. A review of micropumps. J. Micromech. Microeng. 2004, 14, R35-R64.

35. Celectricon Simply Stimulating Homepage. Available online: http://www.cellectricon.se (accessed on 28 February 2012).

36. Beebe, D.J.; Moore, J.S.; Yu, Q.; Liu, R.H.; Kraft, M.L.; Jo, B.H.; Devadoss, C. Microfluidic tectonics: A comprehensive construction platform for microfluidic systems. Proc. Natl. Acad. Sci. USA 2000, 97, 13488-13493.

37. Yu, C.; Parikh, A.N.; Groves, J.T. Direct patterning of membrane-derivatized colloids using in situ UV-ozone photolithography. Adv. Mater. 2005, 17, 1477-1480.

38. Yang, M.; Li, C.W.; Yang, J. Cell docking and on-chip monitoring of cellular reactions with a controlled concentration gradient on a microfluidic device. Anal. Chem. 2002, 74, 3991-4001.

39. Clarson, S.J.; Semlyen, J.A.; Clarson, S.J. Siloxane Polymers; Prentice Hall: Englewood Cliffs, NJ, USA, 1993.

40. Kim, P.; Jeong, H.E.; Khademhosseini, A.; Suh, K.Y. Fabrication of non-biofouling polyethylene glycol micro-and nanochannels by ultraviolet-assisted irreversible sealing. Lab Chip 2006, 6, $1432-1437$.

41. Kaneta, T.; Ogura, T.; Yamato, S.; Imasaka, T. Band broadening of DNA fragments isolated by polyacrylamide gel electrophoresis in capillary electrophoresis. J. Sep. Sci. 2012, 35, 431-435.

42. Li, P.C.H.; Harrison, D.J. Transport, manipulation, and reaction of biological cells on-chip using electrokinetic effects. Anal. Chem. 1997, 69, 1564-1568.

43. Waters, L.C.; Jacobson, S.C.; Kroutchinina, N.; Khandurina, J.; Foote, R.S.; Ramsey, J.M. Microchip device for cell lysis, multiplex PCR amplification, and electrophoretic sizing. Anal. Chem. 1998, 70, 158-162.

44. Ichiki, T.; Ujiie, T.; Shinbashi, S.; Okuda, T.; Horiike, Y. Immunoelectrophoresis of red blood cells performed on microcapillary chips. Electrophoresis 2002, 23, 2029-2034.

45. Lee, H.; Sun, E.; Ham, D.; Weissleder, R. Chip-NMR biosensor for detection and molecular analysis of cells. Nat. Med. 2008, 14, 869-874.

46. Qu, B.Y.; Wu, Z.Y.; Fang, F.; Bai, Z.M.; Yang, D.Z.; Xu, S.K. A glass microfluidic chip for continuous blood cell sorting by a magnetic gradient without labeling. Anal. Bioanal. Chem. 2008, 392, 1317-1324.

47. Omasu, F.; Nakano, Y.; Ichiki, T. Measurement of the electrophoretic mobility of sheep erythrocytes using microcapillary chips. Electrophoresis 2005, 26, 1163-1167.

48. Pilarski, P.M.; Adamia, S.; Backhouse, C.J. An adaptable microvalving system for on-chip polymerase chain reactions. J. Immunol. Methods 2005, 305, 48-58.

49. Unger, M.A.; Chou, H.P.; Thorsen, T.; Scherer, A.; Quake, S.R. Monolithic microfabricated valves and pumps by multilayer soft lithography. Science 2000, 288, 113-116. 
50. Harrison, D.J.; Fluri, K.; Seiler, K.; Fan, Z.; Effenhauser, C.S.; Manz, A. Micromachining a miniaturized capillary electrophoresis-based chemical analysis system on a chip. Science 1993, 261, 895-897.

51. Raley, N.F.; Davidson, J.C.; Balch, J.W. Examination of glass-silicon and glass-glass bonding techniques for microfluidic systems. Proc. SPIE 1995, 2639, 40-45.

52. Kopp, M.U.; de Mello, A.J.; Manz, A. Chemical amplification: Continuous-flow PCR on a chip. Science 1998, 280, 1046-1048.

53. Stjernström, M.; Roeraade, J. Method for fabrication of microfluidic systems in glass. J. Micromech. Microeng. 1998, 8, 33-38.

54. Bings, N.H.; Wang, C.; Skinner, C.D.; Colyer, C.L.; Thibault, P.; Harrison, D.J. Microfluidic devices connected to fused-silica capillaries with minimal dead volume. Anal. Chem. 1999, 71, 3292-3296.

55. Ruano, J.M.; Benoit, V.; Aitchison, J.S.; Cooper, J.M. Flame hydrolysis deposition of glass on silicon for the integration of optical and microfluidic devices. Anal. Chem. 2000, 72, 1093-1097.

56. Grover, W.H.; Skelley, A.M.; Liu, C.N.; Lagally, E.T.; Mathies, R.A. Monolithic membrane valves and diaphragm pumps for practical large-scale integration into glass microfluidic devices. Sens. Actuators B Chem. 2003, 89, 315-323.

57. Jia, Z.J.; Fang, Q.; Fang, Z.L. Bonding of glass microfluidic chips at room temperatures. Anal. Chem. 2004, 76, 5597-5602.

58. Cheng, Y.; Sugioka, K.; Midorikawa, K. Microfluidic laser embedded in glass by three-dimensional femtosecond laser microprocessing. Opt. Lett. 2004, 29, 2007-2009.

59. Bu, M.; Melvin, T.; Ensell, G.J.; Wilkinson, J.S.; Evans, A.G.R. A new masking technology for deep glass etching and its microfluidic application. Sens. Actuators A Phys. 2004, 115, 476-482.

60. Allen, P.B.; Chiu, D.T. Calcium-assisted glass-to-glass bonding for fabrication of glass microfluidic devices. Anal. Chem. 2008, 80, 7153-7157.

61. Vulto, P.; Huesgen, T.; Albrecht, B.; Urban, G. A full-wafer fabrication process for glass microfluidic chips with integrated electroplated electrodes by direct bonding of dry film resist. J. Micromech. Microeng. 2009, 19, 077001:1-077001:5.

62. Giordano, B.; Ferrance, J.; Swedberg, S.; Hühmer, A.; Landers, J. Polymerase chain reaction in polymeric microchips: DNA amplification in less than 240 seconds. Anal. Biochem. 2001, 291, 124-132.

63. Rossier, J.; Reymond, F.; Michel, P.E. Polymer microfluidic chips for electrochemical and biochemical analyses. Electrophoresis 2002, 23, 858-867.

64. Cao, H.; Tegenfeldt, J.O.; Austin, R.H.; Chou, S.Y. Gradient nanostructures for interfacing microfluidics and nanofluidics. Appl. Phys. Lett. 2002, 81, 3058-3060.

65. Mappes, T.; Achenbach, S.; Mohr, J. X-ray lithography for devices with high aspect ratio polymer submicron structures. Microelectron. Eng. 2007, 84, 1235-1239.

66. Becker, H.; Heim, U. Hot embossing as a method for the fabrication of polymer high aspect ratio structures. Sens. Actuators A Phys. 2000, 83, 130-135.

67. Qi, S.; Liu, X.; Ford, S.; Barrows, J.; Thomas, G.; Kelly, K.; McCandless, A.; Lian, K.; Goettert, J.; Soper, S.A. Microfluidic devices fabricated in poly(methyl methacrylate) using 
hot-embossing with integrated sampling capillary and fiber optics for fluorescence detection. Lab Chip 2002, 2, 88-95.

68. Chien, R.D. Micromolding of biochip devices designed with microchannels. Sens. Actuators A Phys. 2006, 128, 238-247.

69. Attia, U.M.; Marson, S.; Alcock, J.R. Micro-injection moulding of polymer microfluidic devices. Microfluid. Nanofluidics 2009, 7, 1-28.

70. Maillefer, D.; Gamper, S.; Frehner, B.; Balmer, P.; van Lintel, H.; Renaud, P. A high-performance silicon micropump for disposable drug delivery systems. In Proceedings of 14th IEEE International Conference on Micro Electro Mechanical Systems, MEMS 2001, Interlaken, Switzerland, 21-25 January 2001; pp. 413-417.

71. Pemble, C.M.; Towe, B.C. A miniature shape memory alloy pinch valve. Sens. Actuators A Phys. 1999, 77, 145-148.

72. Weibel, D.B.; Siegel, A.C.; Lee, A.; George, A.H.; Whitesides, G.M. Pumping fluids in microfluidic systems using the elastic deformation of poly(dimethylsiloxane). Lab Chip 2007, 7, $1832-1836$.

73. Weibel, D.B.; Kruithof, M.; Potenta, S.; Sia, S.K.; Lee, A.; Whitesides, G.M. Torque-actuated valves for microfluidics. Anal. Chem. 2005, 77, 4726-4733.

74. Sundararajan, N.; Kim, D.; Berlin, A.A. Microfluidic operations using deformable polymer membranes fabricated by single layer soft lithography. Lab Chip 2005, 5, 350-354.

75. Studer, V.; Hang, G.; Pandolfi, A.; Ortiz, M.; Anderson, W.F.; Quake, S.R. Scaling properties of a low-actuation pressure microfluidic valve. J. Appl. Phys. 2004, 95, 393-398.

76. Hosokawa, K.; Maeda, R. A pneumatically-actuated three-way microvalve fabricated with polydimethylsiloxane using the membrane transfer technique. J. Micromech. Microeng. 2000, 10, 415-420.

77. Yang, B.; Lin, Q. A latchable microvalve using phase change of paraffin wax. Sens. Actuators A Phys. 2007, 134, 194-200.

78. Yoo, J.C.; Choi, Y.; Kang, C.; Kim, Y.S. A novel polydimethylsiloxane microfluidic system including thermopneumatic-actuated micropump and paraffin-actuated microvalve. Sens. Actuators A Phys. 2007, 139, 216-220.

79. Irimia, D.; Toner, M. Cell handling using microstructured membranes. Lab Chip 2006, 6, 345-352.

80. Van der Wijngaart, W.; Chugh, D.; Man, E.; Melin, J.; Stemme, G. A low-temperature thermopneumatic actuation principle for gas bubble microvalves. J. Microelectromech. Syst. 2007, 16, 765-774.

81. Lee, D.E.; Soper, S.; Wang, W. Design and fabrication of an electrochemically actuated microvalve. Microsyst. Technol. 2008, 14, 1751-1756.

82. Kaigala, G.V.; Hoang, V.N.; Backhouse, C.J. Electrically controlled microvalves to integrate microchip polymerase chain reaction and capillary electrophoresis. Lab Chip 2008, 8, 1071-1078.

83. Jacobson, S.C.; Ermakov, S.V.; Ramsey, J.M. Minimizing the number of voltage sources and fluid reservoirs for electrokinetic valving in microfluidic devices. Anal. Chem. 1999, 71, 3273-3276.

84. Schasfoort, R.B.M.; Schlautmann, S.; Hendrikse, J.; van den Berg, A. Field-effect flow control for microfabricated fluidic networks. Science 1999, 286, 942-945. 
85. Liu, R.H.; Bonanno, J.; Yang, J.; Lenigk, R.; Grodzinski, P. Single-use, thermally actuated paraffin valves for microfluidic applications. Sens. Actuators B Chem. 2004, 98, 328-336.

86. Gui, L.; Liu, J. Ice valve for a mini/micro flow channel. J. Micromech. Microeng. 2004, 14, $242-246$.

87. Yu, Q.; Bauer, J.M.; Moore, J.S.; Beebe, D.J. Responsive biomimetic hydrogel valve for microfluidics. Appl. Phys. Lett. 2001, 78, 2589-2591.

88. Liu, C.; Park, J.Y.; Xu, Y.; Lee, S.H. Arrayed pH-responsive microvalves controlled by multiphase laminar flow. J. Micromech. Microeng. 2007, 17, 1985-1991.

89. Cho, H.; Kim, H.Y.; Kang, J.Y.; Kim, T.S. How the capillary burst microvalve works. J. Colloid Interface Sci. 2007, 306, 379-385.

90. Chen, J.M.; Huang, P.C.; Lin, M.G. Analysis and experiment of capillary valves for microfluidics on a rotating disk. Microfluidics Nanofluidics 2008, 4, 427-437.

91. Riegger, L.; Mielnik, M.; Gulliksen, A.; Mark, D.; Steigert, J.; Lutz, S.; Clad, M.; Zengerle, R.; Koltay, P.; Hoffmann, J. Dye-based coatings for hydrophobic valves and their application to polymer labs-on-a-chip. J. Micromech. Microeng. 2010, 20, 045021:1-045021:6.

92. Allain, M.; Berthier, J.; Basrour, S.; Pouteau, P. Electrically actuated sacrificial membranes for valving in microsystems. J. Micromech. Microeng. 2010, 20, 035006:1-035006:7.

93. Moreno, J.M.; Quero, J.M. A Novel single-use SU-8 microvalve for pressure-driven microfluidic applications. J. Micromech. Microeng. 2010, 20, 015005:1-015005:11.

94. Daniel, K.; Duc, H.L.H.; Cima, M.; Langer, R. Controlled release microchips. Chronopharmaceutics 2009, 187-215.

95. Juncker, D.; Schmid, H.; Drechsler, U.; Wolf, H.; Wolf, M.; Michel, B.; de Rooij, N.; Delamarche, E. Autonomous microfluidic capillary system. Anal. Chem. 2002, 74, 6139-6144.

96. Walker, G.M.; Beebe, D.J. A passive pumping method for microfluidic devices. Lab Chip 2002, 2, 131-134.

97. Schönfeld, F.; Hessel, V.; Hofmann, C. An optimised split-and-recombine micro-mixer with uniform "chaotic" mixing. Lab Chip 2004, 4, 65-69.

98. Jacobson, S.C.; Ramsey, J.M. Integrated microdevice for DNA restriction fragment analysis. Anal. Chem. 1996, 68, 720-723.

99. Yuen, P.K.; Kricka, L.J.; Fortina, P.; Panaro, N.J.; Sakazume, T.; Wilding, P. Microchip module for blood sample preparation and nucleic acid amplification reactions. Genome Res. 2001, 11, $405-412$.

100. Kozlowski, F.; Lindmair, N.; Scheiter, T.; Hierold, C.; Lang, W. A novel method to avoid sticking of surface-micromachined structures. Sens. Actuators A Phys. 1996, 54, 659-662.

101. Steiner, P.; Lang, W. Micromachining applications of porous silicon. Thin Solid Films 1995, 255, 52-58.

102. De Boer, M.J.; Tjerkstra, R.W.; Berenschot, J.; Jansen, H.V.; Burger, G.; Gardeniers, J.; Elwenspoek, M.; van den Berg, A. Micromachining of buried micro channels in silicon. J. Microelectromech. Syst. 2000, 9, 94-103.

103. Schwarz, A.; Rossier, J.; Bianchi, F.; Reymond, F.; Ferrigno, R.; Girault, H. Micro-TAS on polymer substrates micromachined by laser photoablation. In Proceedings of the $\mu$ TAS'98 Workshop, Banff, AB, Canada, 13-16 October 1998; pp. 241-244. 
104. Becker, H.; Klotzbuecher, T. Polymer nanowell plates with variable slope angles. In Proceedings of the 3rd International Conference on Microreaction Technology, Frankfurt, Germany, 19-21 April 1999.

105. Pethig, R.; Burt, J.; Parton, A.; Rizvi, N.; Talary, M.; Tame, J. Development of biofactory-on-a-chip technology using excimer laser micromachining. J. Micromech. Microeng. 1998, 8, 57-63.

106. Roberts, M.A.; Rossier, J.S.; Bercier, P.; Girault, H. UV Laser machined polymer substrates for the development of microdiagnostic systems. Anal. Chem. 1997, 69, 2035-2042.

107. Rötting, O.; Röpke, W.; Becker, H.; Gärtner, C. Polymer microfabrication technologies. Microsyst. Technol. 2002, 8, 32-36.

108. Becker, H.; Dietz, W. Microfluidic devices for $\mu$-TAS applications fabricated by polymer hot embossing. Proc. SPIE 1998, 3515, 177-182.

109. Shao, P.; van Kan, A.; Wang, L.; Ansari, K.; Bettiol, A.; Watt, F. Fabrication of enclosed nanochannels in poly(methylmethacrylate) using proton beam writing and thermal bonding. Appl. Phys. Lett. 2006, 88, 093515:1-093515:4.

110. Schift, H.; Heyderman, L.; Padeste, C.; Gobrecht, J. Chemical nano-patterning using hot embossing lithography. Microelectron. Eng. 2002, 61, 423-428.

111. Heckele, M.; Schomburg, W. Review on micro molding of thermoplastic polymers. J. Micromech. Microeng. 2004, 14, R1-R14.

112. Worgull, M.; Heckele, M.; Schomburg, W. Large-scale hot embossing. Microsyst. Technol. 2005, 12, 110-115.

113. Grund, T.; Heckele, M.; Kohl, M. Batch fabrication methods for polymer-based active microsystems using hot embossing and transfer bonding strategies. In Proceedings of Multi-Material Micro Manufacture, Cardiff, UK, 9-11 September 2008.

114. Park, D.S.W.; Hupert, M.; Witek, M.; You, B.; Datta, P.; Guy, J.; Lee, J.B.; Soper, S.; Nikitopoulos, D.; Murphy, M. A titer plate-based polymer microfluidic platform for high throughput nucleic acid purification. Biomed. Microdevices 2008, 10, 21-33.

115. Park, D.S.W.; Chen, P.C.; You, B.H.; Kim, N.; Park, T.; Lee, T.Y.; Datta, P.; Desta, Y.; Soper, S.A.; Nikitopoulos, D.E. Titer plate formatted continuous flow thermal reactors for high throughput applications: Fabrication and testing. J. Micromech. Microeng. 2010, 20, 055003:1-055003:11.

116. Hardt, D.E.; Hale, M. Development of a Low-Cost, Rapid-Cycle Hot Embossing System for Microscale Parts; Massachusetts Institute of Technology: Cambridge, MA, USA, 2009; Available online: http://hdl.handle.net/1721.1/50565 (accessed on 25 June 2012).

117. Liu, S.J.; Huang, C.C.; Liao, C.T. Continuous infrared-assisted double-sided roll-to-roll embossing of flexible polymer substrates. Polym. Eng. Sci. 2012, 52, 1395-1401.

118. Su, Y.C.; Shah, J.; Lin, L. Implementation and analysis of polymeric microstructure replication by micro injection molding. J. Micromech. Microeng. 2004, 14, 415-422.

119. Yao, D.; Kim, B. Development of rapid heating and cooling systems for injection molding applications. Polym. Eng. Sci. 2002, 42, 2471-2481.

120. Lee, B.K.; Kwon, T.H. A Novel monolithic fabrication method for a plastic microfluidic chip with liquid interconnecting ports. J. Micromech. Microeng. 2010, 20, 105004:1-105004:11. 
121. Mecomber, J.S.; Stalcup, A.M.; Hurd, D.; Halsall, H.B.; Heineman, W.R.; Seliskar, C.J.; Wehmeyer, K.R.; Limbach, P.A. Analytical performance of polymer-based microfluidic devices fabricated by computer numerical controlled machining. Anal. Chem. 2006, 78, 936-941.

122. Thiel, A.; Scheffold, A.; Radbruch, A. Immunomagnetic cell sorting-pushing the limits. Immunotechnology 1998, 4, 89-96.

123. Luo, X.; Cheng, K.; Webb, D.; Wardle, F. Design of ultraprecision machine tools with applications to manufacture of miniature and micro components. J. Mater. Process. Technol. 2005, 167, 515-528.

124. Okazaki, K. Micromachine tool to machine micro-parts. In Proceedings of the ASPE Annual Meeting, Scottsdale, AZ, USA, 22-27 October 2000; pp. 197-204.

125. Miao, J.; Chen, G.; Lai, X.; Li, H.; Li, C. Review of dynamic issues in micro-end-milling. Int. J. Adv. Manuf. Technol. 2007, 31, 897-904.

126. Hupert, M.L.; Guy, W.J.; Llopis, S.D.; Shadpour, H.; Rani, S.; Nikitopoulos, D.E.; Soper, S.A. Evaluation of micromilled metal mold masters for the replication of microchip electrophoresis devices. Microfluid. Nanofluidics 2007, 3, 1-11.

127. Wilding, P.; Kricka, L.J.; Cheng, J.; Hvichia, G.; Shoffner, M.A.; Fortina, P. Integrated cell isolation and polymerase chain reaction analysis using silicon microfilter chambers. Anal. Biochem. 1998, 257, 95-100.

128. Park, T.; Zimmerman, T.J.; Park, D.; Lowrey, B.; Murphy, M.C. Thermoplastic fusion bonding of polymer-based micro devices using a pressure cooker. In Proceedings of the ASME IMECE, Lake Buena Vista, FL, USA, 13-19 November 2009; pp. 295-300.

129. Sniadecki, N.J.; Lamb, C.M.; Liu, Y.; Chen, C.S.; Reich, D.H. Magnetic microposts for mechanical stimulation of biological cells: Fabrication, characterization, and analysis. Rev. Sci. Instrum. 2008, 79, 044302:1-044302:8.

130. Häfeli, U. Scientific and Clinical Applications of Magnetic Carriers; Plenum Press: New York, NY, USA, 1997.

131. Berger, M.; Castelino, J.; Huang, R.; Shah, M.; Austin, R.H. Design of a microfabricated magnetic cell separator. Electrophoresis 2001, 22, 3883-3892.

132. Lee, H.; Purdon, A.; Westervelt, R. Manipulation of biological cells using a microelectromagnet matrix. Appl. Phys. Lett. 2004, 85, 1063-1065.

133. Miltenyi, S.; Müller, W.; Weichel, W.; Radbruch, A. High gradient magnetic cell separation with MACS. Cytometry 1990, 11, 231-238.

134. Toner, M.; Irimia, D. Blood-on-a-chip. Annu. Rev. Biomed. Eng. 2005, 7, 77-103.

135. Furdui, V.I.; Harrison, D.J. Immunomagnetic T cell capture from blood for PCR analysis using microfluidic systems. Lab Chip 2004, 4, 614-618.

136. Grodzinski, P.; Yang, J.; Liu, R.; Ward, M. A modular microfluidic system for cell pre-concentration and genetic sample preparation. Biomed. Microdevices 2003, 5, 303-310.

137. Inglis, D.W.; Riehn, R.; Austin, R.; Sturm, J. Continuous microfluidic immunomagnetic cell separation. Appl. Phys. Lett. 2004, 85, 5093-5095.

138. Miltenyibiotec Homepage. Available online: http://www.miltenyibiotec.com (accessed on 28 February 2012). 
139. Zborowski, M.; Sun, L.; Moore, L.R.; Stephen Williams, P.; Chalmers, J.J. Continuous Cell separation using novel magnetic quadrupole flow sorter. J. Magn. Magn. Mater. 1999, 194, 224-230.

140. Murayama, A.; Furuta, T.; Hyomi, K.; Souma, I.; Oka, Y.; Dagnelund, D.; Buyanova, I.; Chen, W. Dynamics of exciton-spin injection, transfer, and relaxation in self-assembled quantum dots of cdse coupled with a diluted magnetic semiconductor layer of $\mathrm{Zn}_{0.80} \mathrm{Mn}_{0.20}$ Se. Phys. Rev. $B$ 2007, 75, 195308-195317.

141. Han, K.H.; Frazier, A.B. Continuous magnetophoretic separation of blood cells in microdevice format. J. Appl. Phys. 2004, 96, 5797-5802.

142. Zborowski, M.; Fuh, C.B.; Green, R.; Sun, L.; Chalmers, J.J. Analytical magnetapheresis of ferritin-labeled lymphocytes. Anal. Chem. 1995, 67, 3702-3712.

143. Zborowski, M.; Ostera, G.R.; Moore, L.R.; Milliron, S.; Chalmers, J.J.; Schechter, A.N. Red blood cell magnetophoresis. Biophys. J. 2003, 84, 2638-2645.

144. Han, K.H.; Frazier, A.B. Paramagnetic capture mode magnetophoretic microseparator for high efficiency blood cell separations. Lab Chip 2006, 6, 265-273.

145. Pamme, N. Magnetism and microfluidics. Lab Chip 2006, 6, 24-38.

146. Pankhurst, Q.A.; Connolly, J.; Jones, S.; Dobson, J. Applications of magnetic nanoparticles in biomedicine. J. Phys. D 2003, 36, R167-R181.

147. Zhu, L.; Zhang, Q.; Feng, H.; Ang, S.; Chau, F.S.; Liu, W.T. Filter-based microfluidic device as a platform for immunofluorescent assay of microbial cells. Lab Chip 2004, 4, 337-341.

148. Mohamed, H.; McCurdy, L.D.; Szarowski, D.H.; Duva, S.; Turner, J.N.; Caggana, M. Development of a rare cell fractionation device: Application for cancer detection. IEEE Trans. NanoBiosci. 2004, 3, 251-256.

149. Moorthy, J.; Beebe, D.J. In situ fabricated porous filters for microsystems. Lab Chip 2003, 3, 62-66.

150. Huang, L.R.; Cox, E.C.; Austin, R.H.; Sturm, J.C. Continuous particle separation through deterministic lateral displacement. Science 2004, 304, 987-990.

151. Khademhosseini, A.; Yeh, J.; Jon, S.; Eng, G.; Suh, K.Y.; Burdick, J.A.; Langer, R. Molded polyethylene glycol microstructures for capturing cells within microfluidic channels. Lab Chip 2004, 4, 425-430.

152. Tani, H.; Maehana, K.; Kamidate, T. Chip-based bioassay using bacterial sensor strains immobilized in three-dimensional microfluidic network. Anal. Chem. 2004, 76, 6693-6697.

153. Revzin, A.; Tompkins, R.G.; Toner, M. Surface engineering with poly(ethylene glycol) photolithography to create high-density cell arrays on glass. Langmuir 2003, 19, 9855-9862.

154. Chronis, N.; Lee, L.P. Electrothermally activated SU-8 microgripper for single cell manipulation in solution. J. Microelectromech. Syst. 2005, 14, 857-863.

155. Yang, J.; Li, C.W.; Yang, M. Hydrodynamic simulation of cell docking in microfluidic channels with different dam structures. Lab Chip 2004, 4, 53-59.

156. Li, C.W.; Cheung, C.N.; Yang, J.; Tzang, C.H.; Yang, M. PDMS-based microfluidic device with multi-height structures fabricated by single-step photolithography using printed circuit board as masters. Analyst 2003, 128, 1137-1142.

157. Lahann, J.; Balcells, M.; Lu, H.; Rodon, T.; Jensen, K.F.; Langer, R. Reactive polymer coatings: A first step toward surface engineering of microfluidic devices. Anal. Chem. 2003, 75, 2117-2122. 
158. Kirby, B.J.; Wheeler, A.R.; Zare, R.N.; Fruetel, J.A.; Shepodd, T.J. Programmable modification of cell adhesion and zeta potential in silica microchips. Lab Chip 2003, 3, 5-10.

159. Cox, J.D.; Curry, M.S.; Skirboll, S.K.; Gourley, P.L.; Sasaki, D.Y. Surface passivation of a microfluidic device to glial cell adhesion: A comparison of hydrophobic and hydrophilic SAM coatings. Biomaterials 2002, 23, 929-935.

160. Murthy, S.K.; Sin, A.; Tompkins, R.G.; Toner, M. Effect of flow and surface conditions on human lymphocyte isolation using microfluidic chambers. Langmuir 2004, 20, 11649-11655.

161. Revzin, A.; Sekine, K.; Sin, A.; Tompkins, R.G.; Toner, M. Development of a microfabricated cytometry platform for characterization and sorting of individual leukocytes. Lab Chip 2005, 5, 30-37.

162. Chang, W.C.; Lee, L.P.; Liepmann, D. Biomimetic technique for adhesion-based collection and separation of cells in a microfluidic channel. Lab Chip 2005, 5, 64-73.

163. Chen, T.; Small, D.A.; McDermott, M.K.; Bentley, W.E.; Payne, G.F. Enzymatic methods for in situ cell entrapment and cell release. Biomacromolecules 2003, 4, 1558-1563.

164. Carlson, R.H.; Gabel, C.V.; Chan, S.S.; Austin, R.H.; Brody, J.P.; Winkelman, J.W. Self-sorting of white blood cells in a lattice. Phys. Rev. Lett. 1997, 79, 2149-2152.

165. Bakajin, O.; Carlson, R.; Chou, C.; Chan, S.; Gabel, C.; Knight, J.; Cox, T.; Austin, R. Sizing, fractionation and mixing of biological objects via microfabricated devices. In Proceedings of Micro Total Analysis Systems, Banff, AB, Canada, 13-16 October 1998; pp. 193-198.

166. Andersson, H.; van der Wijngaart, W.; Enoksson, P.; Stemme, G. Micromachined flow-through filter-chamber for chemical reactions on beads. Sens. Actuators B Chem. 2000, 67, 203-208.

167. Gossett, D.R.; Weaver, W.M.; Mach, A.J.; Hur, S.C.; Tse, H.T.K.; Lee, W.; Amini, H.; Di Carlo, D. Label-free cell separation and sorting in microfluidic systems. Anal. Bioanal. Chem. 2010, 397, 3249-3267.

168. Ji, H.M.; Samper, V.; Chen, Y.; Heng, C.K.; Lim, T.M.; Yobas, L. Silicon-based microfilters for whole blood cell separation. Biomed. Microdevices 2008, 10, 251-257.

169. Rusu, C.; van Oever, R.; de Boer, M.J.; Jansen, H.V.; Berenschot, J.; Bennink, M.L.; Kanger, J.S.; de Grooth, B.G.; Elwenspoek, M.; Greve, J. Direct integration of micromachined pipettes in a flow channel for single DNA molecule study by optical tweezers. J. Microelectromech. Syst. 2001, 10, 238-246.

170. Dennison, C. Principles of electrophoresis. In A Guide to Protein Isolation; Springer: Berlin, Germany, 2003; pp. 115-149.

171. Manz, A.; Effenhauser, C.S.; Burggraf, N.; Harrison, D.J.; Seiler, K.; Fluri, K. Electroosmotic pumping and electrophoretic separations for miniaturized chemical analysis systems. J. Micromech. Microeng. 1994, 4, 257-265.

172. Ramsey, J.M.; Jacobson, S.C.; Knapp, M.R. Microfabricated chemical measurement systems. Nat. Med. 1995, 1, 1093-1095.

173. Fu, A.Y.; Spence, C.; Scherer, A.; Arnold, F.H.; Quake, S.R. A microfabricated fluorescence-activated cell sorter. Nat. Biotechnol. 1999, 17, 1109-1111.

174. Umehara, S.; Wakamoto, Y.; Inoue, I.; Yasuda, K. On-chip single-cell microcultivation assay for monitoring environmental effects on isolated cells. Biochem. Biophys. Res. Commun. 2003, 305, 534-540. 
175. Enger, J.; Goksör, M.; Ramser, K.; Hagberg, P.; Hanstorp, D. Optical tweezers applied to a microfluidic system. Lab Chip 2004, 4, 196-200.

176. Chou, C.F.; Tegenfeldt, J.O.; Bakajin, O.; Chan, S.S.; Cox, E.C.; Darnton, N.; Duke, T.; Austin, R.H. Electrodeless dielectrophoresis of single-and double-stranded DNA. Biophys. J. 2002, 83, 2170-2179.

177. Fiedler, S.; Shirley, S.G.; Schnelle, T.; Fuhr, G. Dielectrophoretic sorting of particles and cells in a microsystem. Anal. Chem. 1998, 70, 1909-1915.

178. Markx, G.H.; Huang, Y.; Zhou, X.F.; Pethig, R. Dielectrophoretic characterization and separation of micro-organisms. Microbiology 1994, 140, 585-591.

179. Cheng, J.; Sheldon, E.L.; Wu, L.; Uribe, A.; Gerrue, L.O.; Carrino, J.; Heller, M.J.; O'Connell, J.P. Preparation and hybridization analysis of DNA/RNA from E. Coli on microfabricated bioelectronic chips. Nat. Biotechnol. 1998, 16, 541-546.

180. Becker, F.F.; Wang, X.B.; Huang, Y.; Pethig, R.; Vykoukal, J.; Gascoyne, P. Separation of human breast cancer cells from blood by differential dielectric affinity. Proc. Natl. Acad. Sci. USA 1995, 92, 860-864.

181. Wang, X.B.; Yang, J.; Huang, Y.; Vykoukal, J.; Becker, F.F.; Gascoyne, P.R.C. Cell separation by dielectrophoretic field-flow-fractionation. Anal. Chem. 2000, 72, 832-839.

182. Xu, J.; Wu, L.; Wang, X. Functional biochips for cell and molecular manipulation. Micro Total Anal. Syst. 2001, 313-314.

183. Huang, Y.; Joo, S.; Duhon, M.; Heller, M.; Wallace, B.; Xu, X. Dielectrophoretic cell separation and gene expression profiling on microelectronic chip arrays. Anal. Chem. 2002, 74, 3362-3371.

184. Voldman, J.; Gray, M.L.; Toner, M.; Schmidt, M.A. A microfabrication-based dynamic array cytometer. Anal. Chem. 2002, 74, 3984-3990.

185. Huang, Y.; Ewalt, K.L.; Tirado, M.; Haigis, R.; Forster, A.; Ackley, D.; Heller, M.J.; O'Connel, J.P.; Krihak, M. Electric manipulation of bioparticles and macromolecules on microfabricated electrodes. Anal. Chem. 2001, 73, 1549-1559.

186. Dürr, M.; Kentsch, J.; Müller, T.; Schnelle, T.; Stelzle, M. Microdevices for manipulation and accumulation of micro-and nanoparticles by dielectrophoresis. Electrophoresis 2003, 24, 722-731.

187. Chou, C.F.; Morgan, M.; Zenhausern, F.; Prinz, C.; Austin, R.H. Electrodeless dielectrophoretic trapping and separation of cells. Micro Total Anal. Syst. 2002, 1, 25-27.

188. Arai, F.; Ichikawa, A.; Ogawa, M.; Fukuda, T.; Horio, K.; Itoigawa, K. High-speed separation system of randomly suspended single living cells by laser trap and dielectrophoresis. Electrophoresis 2001, 22, 283-288.

189. Cui, L.; Holmes, D.; Morgan, H. The dielectrophoretic levitation and separation of latex beads in microchips. Electrophoresis 2001, 22, 3893-3901.

190. Li, H.; Bashir, R. Dielectrophoretic separation and manipulation of live and heat-treated cells of listeria on microfabricated devices with interdigitated electrodes. Sens. Actuators B Chem. 2002, 86, 215-221.

191. Li, Y.; Kaler, K.V.I.S. Dielectrophoretic fluidic cell fractionation system. Anal. Chim. Acta 2004, 507, 151-161.

192. Seger, U.; Gawad, S.; Johann, R.; Bertsch, A.; Renaud, P. Cell immersion and cell dipping in microfluidic devices. Lab Chip 2004, 4, 148-151. 
193. Hultström, J.; Manneberg, O.; Dopf, K.; Hertz, H.; Brismar, H.; Wiklund, M. Proliferation and viability of adherent cells manipulated by standing-wave ultrasound in a microfluidic chip. Ultrasound Med. Biol. 2007, 33, 145-151.

194. Bazou, D.; Kuznetsova, L.A.; Coakley, W.T. Physical enviroment of 2-D animal cell aggregates formed in a short pathlength ultrasound standing wave trap. Ultrasound Med. Biol. 2005, 31, 423-430.

195. Evander, M.; Johansson, L.; Lilliehorn, T.; Piskur, J.; Lindvall, M.; Johansson, S.; Almqvist, M.; Laurell, T.; Nilsson, J. Noninvasive acoustic cell trapping in a microfluidic perfusion system for online bioassays. Anal. Chem. 2007, 79, 2984-2991.

196. Liu, J.; Kuznetsova, L.A.; Edwards, G.O.; Xu, J.; Ma, M.; Purcell, W.M.; Jackson, S.K.; Coakley, W.T. Functional three-dimensional HepG2 aggregate cultures generated from an ultrasound trap: Comparison with HepG2 spheroids. J. Cell. Biochem. 2007, 102, 1180-1189.

197. Bazou, D.; Blain, E.J.; Coakley, W.T. NCAM and PSA-NCAM dependent membrane spreading and F-Actin reorganization in suspended adhering neural cells. Mol. Membr. Biol. 2008, 25, $102-114$.

198. Edwards, G.O.; Bazou, D.; Kuznetsova, L.A.; Coakley, W.T. Cell adhesion dynamics and actin cytoskeleton reorganization in HepG2 cell aggregates. Cell Commun. Adhes. 2007, 14, 9-20.

199. Gherardini, L.; Cousins, C.M.; Hawkes, J.J.; Spengler, J.; Radel, S.; Lawler, H.; Devcic-Kuhar, B.; Gröschl, M.; Coakley, W.T.; McLoughlin, A.J. A new immobilisation method to arrange particles in a gel matrix by ultrasound standing waves. Ultrasound Med. Biol. 2005, 31, 261-272.

200. Bazou, D.; Coakley, W.T.; Hayes, A.; Jackson, S.K. Long-term viability and proliferation of alginate-encapsulated 3-D HepG2 aggregates formed in an ultrasound trap. Toxicol. in vitro 2008, 22, 1321-1331.

201. Ruedas-Rama, M.J.; Domínguez-Vidal, A.; Radel, S.; Lendl, B. Ultrasonic trapping of microparticles in suspension and reaction monitoring using raman microspectroscopy. Anal. Chem. 2007, 79, 7853-7857.

202. Ashkin, A.; Dziedzic, J.; Yamane, T. Optical trapping and manipulation of single cells using infrared laser beams. Nature 1987, 330, 769-771.

203. Arai, F.; Ng, C.; Maruyama, H.; Ichikawa, A.; El-Shimy, H.; Fukuda, T. On chip single-cell separation and immobilization using optical tweezers and thermosensitive hydrogel. Lab Chip 2005, 5, 1399-1403.

204. Kovac, J.; Voldman, J. Intuitive, image-based cell sorting using optofluidic cell sorting. Anal. Chem. 2007, 79, 9321-9330.

205. Arai, Y.; Yasuda, R.; Akashi, K.; Harada, Y.; Miyata, H.; Kinosita, K.; Itoh, H. Tying a molecular knot with optical tweezers. Nature 1999, 399, 446-448.

206. Smith, S.B.; Cui, Y.; Bustamante, C. Overstretching B-DNA: The elastic response of individual double-stranded and single-stranded DNA molecules. Science 1996, 271, 795-799.

207. Rodrigo, P.; Eriksen, R.; Daria, V.; Glueckstad, J. Interactive light-driven and parallel manipulation of inhomogeneous particles. Opt. Express 2002, 10, 1550-1556.

208. Flynn, R.A.; Birkbeck, A.L.; Gross, M.; Ozkan, M.; Shao, B.; Wang, M.M.; Esener, S.C. Parallel transport of biological cells using individually addressable VCSEL arrays as optical tweezers. Sens. Actuators B Chem. 2002, 87, 239-243. 
209. Birkbeck, A.L.; Flynn, R.A.; Ozkan, M.; Song, D.; Gross, M.; Esener, S.C. VCSEL arrays as micromanipulators in chip-based biosystems. Biomed. Microdevices 2003, 5, 47-54.

210. Ozkan, M.; Wang, M.; Ozkan, C.; Flynn, R.; Esener, S. Optical manipulation of objects and biological cells in microfluidic devices. Biomed. Microdevices 2003, 5, 61-67.

211. MacDonald, M.; Spalding, G.; Dholakia, K. Microfluidic sorting in an optical lattice. Nature 2003, 426, 421-424.

212. Ramser, K.; Wenseleers, W.; Dewilde, S.; van Doorslaer, S.; Moens, L. The combination of resonance raman spectroscopy, optical tweezers and microfluidic systems applied to the study of various heme-containing single cells. Spectroscopy 2008, 22, 287-295.

213. Alrifaiy, A.; Ramser, K. How to integrate a micropipette into a closed microfluidic system: Absorption spectra of an optically trapped erythrocyte. Biomed. Opt. Express 2011, 2, 2299-2306.

214. Moldavan, A. Photo-electric technique for the counting of microscopical cells. Science 1934, 80, 188-189.

215. Crosland-Taylor, P. A device for counting small particles suspended in a fluid through a tube. Nature 1953, 171, 37-38.

216. Coulter, W.H. High speed automatic blood cell counter and cell size analyzer. Proc. Natl. Electron. Conf. 1956, 12, 1034-1042.

217. Fulwyler, M.J. Electronic separation of biological cells by volume. Science 1965, 150, 910-911.

218. Kamentsky, L.A.; Melamed, M.R.; Derman, H. Spectrophotometer: New instrument for ultrarapid cell analysis. Science 1965, 150, 630-631.

219. Kamentsky, L.A.; Melamed, M.R. Spectrophotometric cell sorter. Science 1967, 156, 1364.

220. Melamed, M.; Mullaney, P.; Shapiro, H. An historical review of the development of Ow cytometry and sorters. Flow Cytometry Sorting 1979, 1-10.

221. Shapiro, H.M.; Leif, R.C. Practical Flow Cytometry; Wiley-Liss: Wilmington, DE, USA, 2003.

222. Lindmo, T.; Peters, D.; Sweet, R. Flow Sorters for Biological Cells. Flow Cytometry and Sorting, 2nd ed.; Wiley-Liss: New York, NY, USA, 1990; pp. 145-169.

223. Herzenberg, L.A.; Herzenberg, L.A. Genetics, FACS, immunology, and redox: A tale of two lives intertwined. Annu. Rev. Immunol. 2004, 22, 1-31.

224. Ormerod, M.G. Flow Cytometry-A Basic Introduction. De Novo software: Los Angeles, CA, USA, 2008. Available online: http://flowbook.denovosoftware.com/ (accessed on 28 February 2012).

225. El-Naggar, A.K. Concurrent flow cytometric analysis of DNA and RNA. Methods Mol. Biol. 2004, 263, 371-384.

226. Rabinovitch, P.; June, C. Intracellular ionized calcium, magnesium, membrane potential, and $\mathrm{pH}$. In Flow Cytometry: A Practical Approach; Oxford University Press: New York, NY, USA, 2000; pp. 203-234.

227. Darzynkiewicz, Z.; Juan, G.; Li, X.; Gorczyca, W.; Murakami, T.; Traganos, F. Cytometry in cell necrobiology: Analysis of apoptosis and accidental cell death (Necrosis). Cytometry 1997, 27, 1-20.

228. Pruitt, S.C.; Mielnicki, L.M.; Stewart, C.C. Analysis of fluorescent protein expressing cells by flow cytometry. Methods Mol. Biol. 2004, 263, 239-258.

229. Edwards, A.D.; Manickasingham, S.P.; Spörri, R.; Diebold, S.S.; Schulz, O.; Sher, A.; Kaisho, T.; Akira, S.; Reis, E.S.C. Microbial recognition via toll-like receptor-dependent 
and-independent pathways determines the cytokine response of murine dendritic cell subsets to CD40 triggering. J. Immunol. 2002, 169, 3652-3660.

230. Suzuki, A.; Zheng, Y.; Fukao, K.; Nakauchi, H.; Taniguchi, H. Liver repopulation by c-Met-Positive stem/progenitor cells isolated from the developing rat liver. Hepatogastroenterology 2004, 51, 423-426.

231. Bomberger, C.; Singh-Jairam, M.; Rodey, G.; Guerriero, A.; Yeager, A.M.; Fleming, W.H.; Holland, H.K.; Waller, E.K. Lymphoid reconstitution after autologous PBSC transplantation with FACS-sorted CD34 hematopoietic progenitors. Blood 1998, 91, 2588-2600.

232. Cran, D.; Johnson, L. The predetermination of embryonic sex using flow cytometrically separated X and Y spermatozoa. Hum. Reprod. Update 1996, 2, 355-363.

233. Gift, E.A.; Park, H.J.; Paradis, G.A.; Demain, A.L.; Weaver, J.C. FACS-based isolation of slowly growing cells: Double encapsulation of yeast in gel microdrops. Nat. Biotechnol. 1996, 14, 884-887.

234. Deere, D.; Shen, J.; Vesey, G.; Bell, P.; Bissinger, P.; Veal, D. Flow cytometry and cell sorting for yeast viability assessment and cell selection. Yeast 1998, 14, 147-160.

235. Wallner, G.; Fuchs, B.; Spring, S.; Beisker, W.; Amann, R. Flow sorting of microorganisms for molecular analysis. Appl. Environ. Microbiol. 1997, 63, 4223-4231.

236. Sekar, R.; Fuchs, B.M.; Amann, R.; Pernthaler, J. Flow sorting of marine bacterioplankton after fluorescence in situ hybridization. Appl. Environ. Microbiol. 2004, 70, 6210-6219.

237. Jochem, F.J. Short-term physiologic effects of mechanical flow sorting and the becton-dickinson cell concentrator in cultures of the marine phytoflagellata emiliania huxleyi and micromonas pusilla. Cytom. A 2005, 65, 77-83.

238. Guasch, R.; Guerri, C.; O'Connor, J. Flow cytometric analysis of concanavalin A binding to isolated golgi fractions from rat liver. Exp. Cell Res. 1993, 207, 136-141.

239. Dolezel, J.; Kubalakova, M.; Cihalikova, J.; Suchankova, P.; Simkova, H. Chromosome analysis and sorting using flow cytometry. Methods Mol. Biol. 2011, 701, 221-238.

240. Ferguson-Smith, M.; Yang, F.; Rens, W.; O'Brien, P. the impact of chromosome sorting and painting on the comparative analysis of primate genomes. Cytogenet. Genome Res. 2005, 108, 112-121.

241. Doležel, J.; Kubalakova, M.; Bartoš, J.; Macas, J. Flow cytogenetics and plant genome mapping. Chromosome Res. 2004, 12, 77-91.

242. Avni, R.D.; Miron, A.; Mok, S.; Randrianarison, V. Generation of chromo-some paints: approach for increasing specificity and intensity of signals. Biotechniques 2003, 34, 530-536.

243. Szaniszlo, P.; Wang, N.; Sinha, M.; Reece, L.M.; van Hook, J.W.; Luxon, B.A.; Leary, J.F. Getting the right cells to the array: Gene expression microarray analysis of cell mixtures and sorted cells. Cytom. A 2004, 59, 191-202.

244. Battye, F.L.; Light, A.; Tarlinton, D.M. Single cell sorting and cloning. J. Immunol. Methods 2000, 243, 25-32.

245. Williams, C.; Davies, D.; Williamson, R. Segregation of $\triangle F 508$ and normal CFTR alleles in human sperm. Hum. Mol. Genet. 1993, 2, 445-448. 
246. Telleman, P.; Larsen, U.; Philip, J.; Blankenstein, G.; Wolff, A. Cell sorting in microfluidic systems. In Proceedings of Micro Total Analysis Systems, Banff, AB, Canada, 13-16 October 1998; pp. 39-44.

247. Blankenstein, G.; Darling Larsen, U. Modular concept of a laboratory on a chip for chemical and biochemical analysis. Biosens. Bioelectron. 1998, 13, 427-438.

248. McClain, M.A.; Culbertson, C.T.; Jacobson, S.C.; Ramsey, J.M. Flow cytometry of escherichia coli on microfluidic devices. Anal. Chem. 2001, 73, 5334-5338.

249. Müller, T.; Gradl, G.; Howitz, S.; Shirley, S.; Schnelle, T.; Fuhr, G. A 3-D Microelectrode system for handling and caging single cells and particles. Biosens. Bioelectron. 1999, 14, 247-256.

250. Fu, A.Y.; Chou, H.P.; Spence, C.; Arnold, F.H.; Stephen, R. An integrated microfabricated cell sorter. Anal. Chem. 2002, 74, 2451-2457.

251. Gradl, G.; Müller, T.; Pfennig, A.; Shirley, S.; Schnelle, T.; Führ, G. New micro device for single cell analysis, cell sorting and cloning on a chip: The cytocon instrument. Micro Total Anal. 2000, 443-446.

252. Muller, T.; Schnelle, T.; Gradl, T.; Pfennig, A.; Fuhr, G. Live cells in cell processors. Bioworld 2002, 2, 12-13.

253. Gawad, S.; Metz, S.; Laurent, S.; Renaud, P. Impedance spectroscopy cell analysis in microchannels. Micro Total Anal. Syst. 2002, 253-255.

254. Nieuwenhuis, J.; Vellekoop, M.J. FEM study of coulter counter with water-based adaptable aperture. Micro Total Anal. Syst. 2002, 67-69.

255. Hayenga, J.; Bardell, R.; Morris, C.; Graham, P.; Kesler, C.; Lancaster, A.; Padmanabhan, A.; Cabuz, C.; Schulte, T.; Weigl, B.; et al. Enabling technologies for a personal flow cytometer. Part II. Integrated analysis cartridges. In Proceedings of the Mocro Total Analysis Systems 2002 Symposium, Nara, Japan, 3-7 November 2002.

256. Kruger, J.; Porta, P.; Morrison, A.; Singh, K.; O’Neill, A.; O’Brien, P. Micro-optical laser induced fluorescence detection on a miniaturized flow cytometry device. In Proceedings of the Mocro Total Analysis Systems 2002 Symposium, Nara, Japan, 3-7 November 2002.

257. Glasgow, I.; Zeringue, H.; Beebe, D.; Choi, S.; Lyman, J.; Wheeler, M. Individual embryo transport and retention on a chip. In Proceedings of the Mocro Total Analysis Systems 2000 Symposium, Ensched, The Netherlans, 14-18 May 2000.

258. Kricka, L.; Nozaki, O.; Heyner, S.; Garside, W.; Wilding, P. Applications of a microfabricated device for evaluating sperm function. Clin. Chem. 1993, 39, 1944-1947.

259. Tracey, M.; Johnston, I.; Greenaway, R.; Davis, J.; Sutton, N.; Doetzel, W. Microfluidics based microcytometer: Interfacing microfluidics with macrofluidics. In Proceedings of the Mocro Total Analysis Systems 1998 Symposium, Banff, Canada, 13-16 October 1998.

260. Takayama, S.; Ostuni, E.; Qian, X.; McDonald, J.C.; Jiang, X.; LeDuc, P.; Wu, M.H.; Ingber, D.E.; Whitesides, G.M. Topographical micropatterning of poly(dimethylsiloxane) using laminar flows of liquids in capillaries. Adv. Mater. 2001, 13, 570-574.

261. Turner, A.; Dowell, N.; Turner, S.; Kam, L.; Isaacson, M.; Turner, J.; Craighead, H.; Shain, W. Attachment of astroglial cells to microfabricated pillar arrays of different geometries. J. Biomed. Mater. Res. 2000, 51, 430-441. 
262. Lu, H.; Koo, L.; Griffith, L.; Jensen, K. Development of microfluidic shear assays for quantitative analysis of cell adhesion. Micro Total Anal. Syst. 2002, 784-786.

263. Monaghan, P.; Manz, A.; Nichols, W. Microbiology on a chip. In Proceedings of the Mocro Total Analysis Systems 2000 Symposium, Ensched, The Netherlans, 14-18 May 2000.

264. Tamaki, E.; Sato, K.; Tokeshi, M.; Sato, K.; Aihara, M.; Kitamori, T. Single-cell analysis by a scanning thermal lens microscope with a microchip: Direct monitoring of cytochrome C distribution during apoptosis process. Anal. Chem. 2002, 74, 1560-1564.

265. DeBusschere, B.D.; Kovacs, G.T.A. Portable cell-based biosensor system using integrated CMOS cell-cartridges. Biosens. Bioelectron. 2001, 16, 543-556.

266. Hediger, S.; Fontannaz, J.; Sayah, A.; Hunziker, W.; Gijs, M.A.M. Biosystem for the culture and characterization of epithelial cell tissues. Sens. Actuators B Chem. 2000, 63, 63-73.

267. Hediger, S.; Sayah, A.; Horisberger, J.D.; Gijs, M.A.M. Modular microsystem for epithelial cell culture and electrical characterisation. Biosens. Bioelectron. 2001, 16, 689-694.

268. Heuschkel, M.O.; Guerin, L.; Buisson, B.; Bertrand, D.; Renaud, P. Buried microchannels in photopolymer for delivering of solutions to neurons in a network. Sens. Actuators B Chem. 1998, $48,356-361$.

269. Xu, J.; Wang, X.; Ensign, B.; Li, M.; Wu, L.; Guia, A.; Xu, J. Ion-channel assay technologies: Quo vadis? Drug Discov. Today 2001, 6, 1278-1287.

270. Schmidt, C.; Mayer, M.; Vogel, H. A chip-based biosensor for the functional analysis of single ion channels. Angew. Chem. 2000, 112, 3267-3270.

271. Lehnert, T.; Gijs, M.A.M.; Netzer, R.; Bischoff, U. Realization of hollow $\mathrm{SiO}_{2}$ micronozzles for electrical measurements on living cells. Appl. Phys. Lett. 2002, 81, 5063-5065.

272. Han, A.; Moss, E.; Rabbitt, R.; Frazier, B. A multi-purpose micro system for electrophysiological analyses of single cells. In Proceedings of the Mocro Total Analysis Systems 2002 Symposium, Nara, Japan, 3-7 November 2002.

273. Farinas, J.; Chow, A.W.; Wada, H.G. A microfluidic device for measuring cellular membrane potential. Anal. Biochem. 2001, 295, 138-142.

274. Walker, G.M.; Zeringue, H.C.; Beebe, D.J. Microenvironment design considerations for cellular scale studies. Lab Chip 2004, 4, 91-97.

275. Mahoney, M.J.; Chen, R.R.; Tan, J.; Mark, S.W. The influence of microchannels on neurite growth and architecture. Biomaterials 2005, 26, 771-778.

276. Walker, G.; Ozers, M.; Beebe, D. Insect cell culture in microfluidic channels. Biomed. Microdevices 2002, 4, 161-166.

277. Li, N.; Tourovskaia, A.; Folch, A. Biology on a chip: Microfabrication for studying the behavior of cultured cells. Crit. Rev. Biomed. Eng. 2003, 31, 423-488.

278. Raty, S.; Walters, E.M.; Davis, J.; Zeringue, H.; Beebe, D.J.; Rodriguez-Zas, S.L.; Wheeler, M.B. Embryonic development in the mouse is enhanced via microchannel culture. Lab Chip 2004, 4, 186-190.

279. Leclerc, E.; Sakai, Y.; Fujii, T. Perfusion culture of fetal human hepatocytes in microfluidic environments. Biochem. Eng. J. 2004, 20, 143-148. 
280. Groisman, A.; Lobo, C.; Cho, H.J.; Campbell, J.K.; Dufour, Y.S.; Stevens, A.M.; Levchenko, A. A microfluidic chemostat for experiments with bacterial and yeast cells. Nat. Methods 2005, 2, 685-689.

281. Balagaddé, F.K.; You, L.; Hansen, C.L.; Arnold, F.H.; Quake, S.R. Long-term monitoring of bacteria undergoing programmed population control in a microchemostat. Science 2005, 309, $137-140$.

282. Thompson, D.M.; King, K.R.; Wieder, K.J.; Toner, M.; Yarmush, M.L.; Jayaraman, A. Dynamic gene expression profiling using a microfabricated living cell array. Anal. Chem. 2004, 76, 4098-4103.

283. Gómez-Sjöberg, R.; Leyrat, A.A.; Pirone, D.M.; Chen, C.S.; Stephen, R. Versatile, fully automated, microfluidic cell culture system. Anal. Chem. 2007, 79, 8557-8563.

284. Toh, Y.C.; Zhang, C.; Zhang, J.; Khong, Y.M.; Chang, S.; Samper, V.D.; van Noort, D.; Hutmacher, D.W.; Yu, H. A novel 3D mammalian cell perfusion-culture system in microfluidic channels. Lab Chip 2007, 7, 302-309.

285. Lee, P.; Lin, R.; Moon, J.; Lee, L.P. Microfluidic alignment of collagen fibers for in vitro cell culture. Biomed. Microdevices 2006, 8, 35-41.

286. Hung, P.J.; Lee, P.J.; Sabounchi, P.; Aghdam, N.; Lin, R.; Lee, L.P. A novel high aspect ratio microfluidic design to provide a stable and uniform microenvironment for cell growth in a high throughput mammalian cell culture array. Lab Chip 2005, 5, 44-48.

287. Taylor, A.M.; Rhee, S.W.; Tu, C.H.; Cribbs, D.H.; Cotman, C.W.; Jeon, N.L. Microfluidic multicompartment device for neuroscience research. Langmuir 2003, 19, 1551-1556.

288. Thiébaud, P.; Lauer, L.; Knoll, W.; Offenhäusser, A. PDMS device for patterned application of microfluids to neuronal cells arranged by microcontact printing. Biosens. Bioelectron. 2002, 17, 87-93.

289. Rhee, S.W.; Taylor, A.M.; Tu, C.H.; Cribbs, D.H.; Cotman, C.W.; Jeon, N.L. Patterned cell culture inside microfluidic devices. Lab Chip 2005, 5, 102-107.

290. Zhu, X.; Chu, L.Y.; Chueh, B.; Shen, M.; Hazarika, B.; Phadke, N.; Takayama, S. Arrays of horizontally-oriented mini-reservoirs generate steady microfluidic flows for continuous perfusion cell culture and gradient generation. Analyst 2004, 129, 1026-1031.

291. Maharbiz, M.M.; Holtz, W.J.; Sharifzadeh, S.; Keasling, J.D.; Howe, R.T. A Microfabricated electrochemical oxygen generator for high-density cell culture arrays. J. Microelectromech. Syst. 2003, 12, 590-599.

292. Tourovskaia, A.; Figueroa-Masot, X.; Folch, A. Differentiation-on-a-chip: A microfluidic platform for long-term cell culture studies. Lab Chip 2005, 5, 14-19.

293. Prokop, A.; Prokop, Z.; Schaffer, D.; Kozlov, E.; Wikswo, J.; Cliffel, D.; Baudenbacher, F. NanoLiterBioReactor: Long-term mammalian cell culture at nanofabricated scale. Biomed. Microdevices 2004, 6, 325-339.

294. Kojima, K.; Moriguchi, H.; Hattori, A.; Kaneko, T.; Yasuda, K. Two-dimensional network formation of cardiac myocytes in agar microculture chip with $1480 \mathrm{~nm}$ infrared laser photo-thermal etching. Lab Chip 2003, 3, 292-296. 
295. Moriguchi, H.; Wakamoto, Y.; Sugio, Y.; Takahashi, K.; Inoue, I.; Yasuda, K. An agar-microchamber cell-cultivation system: Flexible change of microchamber shapes during cultivation by photo-thermal etching. Lab Chip 2002, 2, 125-132.

296. Tan, W.; Desai, T.A. Layer-by-layer microfluidics for biomimetic three-dimensional structures. Biomaterials 2004, 25, 1355-1364.

297. Leclerc, E.; Furukawa, K.; Miyata, F.; Sakai, Y.; Ushida, T.; Fujii, T. Fabrication of microstructures in photosensitive biodegradable polymers for tissue engineering applications. Biomaterials 2004, 25, 4683-4690.

298. Sakai, Y.; Leclerc, E.; Fujii, T. Microfluidic cell-culture devices. Lab-on-Chips Cellomics; Springer: Amsterdam, The Netherlands, 2004; pp. 299-318.

299. Martin, K.; Henkel, T.; Baier, V.; Grodrian, A.; Schön, T.; Roth, M.; Köhler, J.M.; Metze, J. Generation of larger numbers of separated microbial populations by cultivation in segmented-flow microdevices. Lab Chip 2003, 3, 202-207.

300. Pearce, T.M.; Wilson, J.A.; Oakes, S.G.; Chiu, S.Y.; Williams, J.C. Integrated microelectrode array and microfluidics for temperature clamp of sensory neurons in culture. Lab Chip 2005, 5, 97-101.

301. Cluzel, P.; Surette, M.; Leibler, S. An ultrasensitive bacterial motor revealed by monitoring signaling proteins in single cells. Science 2000, 287, 1652-1655.

302. Yamaguchi, Y.; Arakawa, T.; Takeda, N.; Edagawa, Y.; Shoji, S. Development of a poly-dimethylsiloxane microfluidic device for single cell isolation and incubation. Sens. Actuators B Chem. 2009, 136, 555-561.

303. Wheeler, A.R.; Throndset, W.R.; Whelan, R.J.; Leach, A.M.; Zare, R.N.; Liao, Y.H.; Farrell, K.; Manger, I.D.; Daridon, A. Microfluidic device for single-cell analysis. Anal. Chem. 2003, 75, 3581-3586.

304. Di Carlo, D.; Wu, L.Y.; Lee, L.P. Dynamic single cell culture array. Lab Chip 2006, 6, 1445-1449.

305. Lee, P.J.; Hung, P.J.; Shaw, R.; Jan, L.; Lee, L.P. Microfluidic application-specific integrated device for monitoring direct cell-cell communication via gap junctions between individual cell pairs. Appl. Phys. Lett. 2005, 86, 223902:1-223902:3.

306. Kang, L.; Chung, B.G.; Langer, R.; Khademhosseini, A. Microfluidics for drug discovery and development: From target selection to product lifecycle management. Drug Discov. Today 2008, $13,1-13$.

307. Zheng, B.; Tice, J.D.; Ismagilov, R.F. Formation of arrayed droplets by soft lithography and two-phase fluid flow, and application in protein crystallization. Adv. Mater. 2004, 16, $1365-1368$.

308. Zheng, W.; Spencer, R.H.; Kiss, L. High throughput assay technologies for ion channel drug discovery. Assay Drug Dev. Technol. 2004, 2, 543-552.

309. Dittrich, P.S.; Manz, A. Lab-on-a-chip: Microfluidics in drug discovery. Nat. Rev. Drug Discov. 2006, 5, 210-218.

310. Maerk1, S.J. Integration column: Microfluidic high-throughput screening. Integr. Biol. 2009, 1, 19-29.

311. Lii, J.; Hsu, W.J.; Parsa, H.; Das, A.; Rouse, R.; Sia, S.K. Real-time microfluidic system for studying mammalian cells in 3D microenvironments. Anal. Chem. 2008, 80, 3640-3647. 
312. Pregibon, D.C.; Toner, M.; Doyle, P.S. Multifunctional encoded particles for high-throughput biomolecule analysis. Science 2007, 315, 1393-1396.

313. Hwang, D.K.; Oakey, J.; Toner, M.; Arthur, J.A.; Anseth, K.S.; Lee, S.; Zeiger, A.; van Vliet, K.J.; Doyle, P.S. Stop-flow lithography for the production of shape-evolving degradable microgel particles. J. Am. Chem. Soc. 2009, 131, 4499-4504.

314. Brouzes, E.; Medkova, M.; Savenelli, N.; Marran, D.; Twardowski, M.; Hutchison, J.B.; Rothberg, J.M.; Link, D.R.; Perrimon, N.; Samuels, M.L. Droplet microfluidic technology for single-cell high-throughput screening. Proc. Natl. Acad. Sci. USA 2009, 106, 14195-14200.

315. Chen, A.A.; Underhill, G.H.; Bhatia, S.N. Multiplexed, high-throughput analysis of 3D microtissue suspensions. Integr. Biol. 2010, 2, 517-527.

316. Choi, N.W.; Cabodi, M.; Held, B.; Gleghorn, J.P.; Bonassar, L.J.; Stroock, A.D. Microfluidic scaffolds for tissue engineering. Nat. Mater. 2007, 6, 908-915.

317. Kumachev, A.; Greener, J.; Tumarkin, E.; Eiser, E.; Zandstra, P.W.; Kumacheva, E. High-throughput generation of hydrogel microbeads with varying elasticity for cell encapsulation. Biomaterials 2011, 32, 1477-1483.

318. Trivedi, V.; Ereifej, E.S.; Doshi, A.; Sehgal, P.; VandeVord, P.J.; Basu, A.S. Microfluidic encapsulation of cells in alginate capsules for high throughput screening. Conf. Proc. IEEE Eng. Med. Biol. Soc. 2009, 7037-7040.

319. Choi, C.H.; Jung, J.H.; Rhee, Y.W.; Kim, D.P.; Shim, S.E.; Lee, C.S. Generation of monodisperse alginate microbeads and in situ encapsulation of cell in microfluidic device. Biomed. Microdevices 2007, 9, 855-862.

320. Chen, W.; Yang, Y.; Rinadi, C.; Zhou, D.; Shen, A.Q. Formation of supramolecular hydrogel microspheres via microfluidics. Lab Chip 2009, 9, 2947-2951.

321. Zeng, S.; Liu, X.; Xie, H.; Lin, B. Basic technologies for droplet microfluidics. Top. Curr. Chem. 2011, 304, 69-90.

322. Song, H.; Chen, D.L.; Ismagilov, R.F. Reactions in droplets in microfluidic channels. Angew. Chem. Int. Ed. 2006, 45, 7336-7356.

323. Tan, Y.C.; Hettiarachchi, K.; Siu, M.; Pan, Y.R.; Lee, A.P. Controlled microfluidic encapsulation of cells, proteins, and microbeads in lipid vesicles. J. Am. Chem. Soc. 2006, 128, 5656-5658.

324. Shah, R.K.; Shum, H.C.; Rowat, A.C.; Lee, D.; Agresti, J.J.; Utada, A.S.; Chu, L.Y.; Kim, J.W.; Fernandez-Nieves, A.; Martinez, C.J. Designer emulsions using microfluidics. Mater. Today 2008, 11, 18-27.

325. Atencia, J.; Beebe, D.J. Controlled microfluidic interfaces. Nature 2005, 437, 648-655.

326. Gong, Z.; Penmetsa, S.; Zheng, Z.; Lvov, Y.; Que, L. Encapsulation of microparticles and biomolecules based on layer-by-layer nanoassembly techniques with microfluidic droplet devices. In Proceedings of Solid-State Sensors, Actuators and Microsystems Conference, TRANSDUCERS 2009, Denver, CO, USA, 21-25 June 2009; pp. 1043-1046.

327. Gong, Z.; Zhao, H.; Zhang, T.; Nie, F.; Pathak, P.; Cui, K.; Wang, Z.; Wong, S.; Que, L. Drug effects analysis on cells using a high throughput microfluidic chip. Biomed. Microdevices 2011, 13, 215-219.

328. Häussinger, D. The role of cellular hydration in the regulation of cell function. Biochem. J. 1996, 313, 697. 
329. Hua, S.Z.; Pennell, T. A microfluidic chip for real-time studies of the volume of single cells. Lab Chip 2009, 9, 251-256.

330. El-Ali, J.; Sorger, P.K.; Jensen, K.F. Cells on chips. Nature 2006, 442, 403-411.

331. Warrick, J.; Meyvantsson, I.; Ju, J.; Beebe, D.J. High-throughput microfluidics: Improved sample treatment and washing over standard wells. Lab Chip 2007, 7, 316-321.

332. Chen, D.L.; Ismagilov, R.F. microfluidic cartridges preloaded with nanoliter plugs of reagents: An alternative to 96-well plates for screening. Curr. Opin. Chem. Biol. 2006, 10, 226-231.

333. Clausell-Tormos, J.; Lieber, D.; Baret, J.C.; El-Harrak, A.; Miller, O.J.; Frenz, L.; Blouwolff, J.; Humphry, K.J.; Köster, S.; Duan, H. Droplet-based microfluidic platforms for the encapsulation and screening of mammalian cells and multicellular organisms. Chem. Biol. 2008, 15, 427-437.

334. Huebner, A.; Bratton, D.; Whyte, G.; Yang, M.; Abell, C.; Hollfelder, F. Static microdroplet arrays: A microfluidic device for droplet trapping, incubation and release for enzymatic and cell-based assays. Lab Chip 2009, 9, 692-698.

335. Huh, D.; Matthews, B.D.; Mammoto, A.; Montoya-Zavala, M.; Hsin, H.Y.; Ingber, D.E. Reconstituting organ-level lung functions on a chip. Science 2010, 328, 1662-1668.

336. Discher, D.E.; Mooney, D.J.; Zandstra, P.W. Growth factors, matrices, and forces combine and control stem cells. Science 2009, 324, 1673-1677.

337. Liu, J.; Gao, D.; Li, H.F.; Lin, J.M. Controlled photopolymerization of hydrogel microstructures inside microchannels for bioassays. Lab Chip 2009, 9, 1301-1305.

338. Cheung, Y.K.; Gillette, B.M.; Zhong, M.; Ramcharan, S.; Sia, S.K. Direct patterning of composite biocompatible microstructures using microfluidics. Lab Chip 2007, 7, 574-579.

339. Qi, H.; Du, Y.; Wang, L.; Kaji, H.; Bae, H.; Khademhosseini, A. Patterned differentiation of individual embryoid bodies in spatially organized 3D hybrid microgels. Adv. Mater. 2010, 22, 5276-5281.

340. Bruzewicz, D.A.; McGuigan, A.P.; Whitesides, G.M. Fabrication of a modular tissue construct in a microfluidic chip. Lab Chip 2008, 8, 663-671.

341. Pautot, S.; Wyart, C.; Isacoff, E.Y. Colloid-guided assembly of oriented 3D neuronal networks. Nat. Methods 2008, 5, 735-740.

342. Chung, S.; Sudo, R.; Mack, P.J.; Wan, C.R.; Vickerman, V.; Kamm, R.D. Cell migration into scaffolds under co-culture conditions in a microfluidic platform. Lab Chip 2009, 9, 269-275.

343. Huang, C.P.; Lu, J.; Seon, H.; Lee, A.P.; Flanagan, L.A.; Kim, H.Y.; Putnam, A.J.; Jeon, N.L. Engineering microscale cellular niches for three-dimensional multicellular co-cultures. Lab Chip 2009, 9, 1740-1748.

344. Carrion, B.; Huang, C.P.; Ghajar, C.M.; Kachgal, S.; Kniazeva, E.; Jeon, N.L.; Putnam, A.J. Recreating the perivascular niche ex vivo using a microfluidic approach. Biotechnol. Bioeng. 2010, 107, 1020-1028.

345. Sudo, R.; Chung, S.; Zervantonakis, I.K.; Vickerman, V.; Toshimitsu, Y.; Griffith, L.G.; Kamm, R.D. Transport-mediated angiogenesis in 3D epithelial coculture. FASEB J. 2009, 23, 2155-2164.

346. Kim, L.; Toh, Y.C.; Voldman, J.; Yu, H. A practical guide to microfluidic perfusion culture of adherent mammalian cells. Lab Chip 2007, 7, 681-694. 
347. Wolbers, F.; ter Braak, P.; le Gac, S.; Luttge, R.; Andersson, H.; Vermes, I.; van den Berg, A. Viability study of HL60 cells in contact with commonly used microchip materials. Electrophoresis 2006, 27, 5073-5080.

348. Davidsson, R.; Boketoft, Å.; Bristulf, J.; Kotarsky, K.; Olde, B.; Owman, C.; Bengtsson, M.; Laurell, T.; Emnéus, J. Developments toward a microfluidic system for long-term monitoring of dynamic cellular events in immobilized human cells. Anal. Chem. 2004, 76, 4715-4720.

349. Blau, A.W.; Ziegler, C.M. Prototype of a novel autonomous perfusion chamber for long-term culturing and in situ investigation of various cell types. J. Biochem. Biophys. Methods 2001, 50, $15-27$.

350. Lee, J.N.; Jiang, X.; Ryan, D.; Whitesides, G.M. Compatibility of mammalian cells on surfaces of poly(dimethylsiloxane). Langmuir 2004, 20, 11684-11691.

351. Futai, N.; Gu, W.; Song, J.W.; Takayama, S. Handheld recirculation system and customized media for microfluidic cell culture. Lab Chip 2006, 6, 149-154.

352. Komen, J.; Wolbers, F.; Franke, H.R.; Andersson, H.; Vermes, I.; van den Berg, A. Viability analysis and apoptosis induction of breast cancer cells in a microfluidic device: Effect of cytostatic drugs. Biomed. Microdevices 2008, 10, 727-737.

353. Yu, H.; Meyvantsson, I.; Shkel, I.A.; Beebe, D.J. Diffusion dependent cell behavior in microenvironments. Lab Chip 2005, 5, 1089-1095.

354. Li, Y.S.J.; Haga, J.H.; Chien, S. Molecular basis of the effects of shear stress on vascular endothelial cells. J. Biomech. 2005, 38, 1949-1971.

355. Healy, Z.R.; Lee, N.H.; Gao, X.; Goldring, M.B.; Talalay, P.; Kensler, T.W.; Konstantopoulos, K. Divergent responses of chondrocytes and endothelial cells to shear stress: Cross-talk among COX-2, the phase 2 response, and apoptosis. Proc. Natl. Acad. Sci. USA 2005, 102, 14010-14015.

356. Wang, M.M.; Tu, E.; Raymond, D.E.; Yang, J.M.; Zhang, H.; Hagen, N.; Dees, B.; Mercer, E.M.; Forster, A.H.; Kariv, I. Microfluidic sorting of mammalian cells by optical force switching. Nat. Biotechnol. 2004, 23, 83-87.

357. Ramser, K.; Hanstorp, D. Optical manipulation for single-cell studies. J. Biophotonics 2010, 3, 187-206.

358. Li, H.; Friend, J.R.; Yeo, L.Y. A scaffold cell seeding method driven by surface acoustic waves. Biomaterials 2007, 28, 4098-4104.

359. Gray, B.L.; Lieu, D.K.; Collins, S.D.; Smith, R.L.; Barakat, A.I. Microchannel platform for the study of endothelial cell shape and function. Biomed. Microdevices 2002, 4, 9-16.

360. Frame, M.D.; Sarelius, I.H. Flow-induced cytoskeletal changes in endothelial cells growing on curved surfaces. Microcirculation 2000, 7, 419-427.

361. Cinamon, G.; Alon, R. A real time in vitro assay for studying leukocyte transendothelial migration under physiological flow conditions. J. Immunol. Methods 2003, 273, 53-62.

362. Frame, M.D.S.; Chapman, G.B.; Makino, Y.; Sarelius, I.H. Shear stress gradient over endothelial cells in a curved microchannel system. Biorheology 1998, 35, 245-262.

363. Schaff, U.Y.; Xing, M.M.Q.; Lin, K.K.; Pan, N.; Jeon, N.L.; Simon, S.I. Vascular mimetics based on microfluidics for imaging the leukocyte-endothelial inflammatory response. Lab Chip 2007, 7, 448-456. 
364. Tanaka, Y.; Kikukawa, Y.; Sato, K.; Sugii, Y.; Kitamori, T. Culture and leukocyte adhesion assay of human arterial endothelial cells in a glass microchip. Anal. Sci. 2007, 23, 261-266.

365. Young, E.W.K.; Wheeler, A.R.; Simmons, C.A. Matrix-dependent adhesion of vascular and valvular endothelial cells in microfluidic channels. Lab Chip 2007, 7, 1759-1766.

366. Ku, C.J.; D’Amico, O.T.; Spence, D.M. Interactions between multiple cell types in parallel microfluidic channels: Monitoring platelet adhesion to an endothelium in the presence of an anti-adhesion drug. Anal. Chem. 2008, 80, 7543-7548.

367. Liu, K.; Pitchimani, R.; Dang, D.; Bayer, K.; Harrington, T.; Pappas, D. Cell culture chip using low-shear mass transport. Langmuir 2008, 24, 5955-5960.

368. Shamloo, A.; Ma, N.; Poo, M.; Sohn, L.L.; Heilshorn, S.C. Endothelial cell polarization and chemotaxis in a microfluidic device. Lab Chip 2008, 8, 1292-1299.

369. Borenstein, J.T.; Terai, H.; King, K.R.; Weinberg, E.; Kaazempur-Mofrad, M.; Vacanti, J. Microfabrication technology for vascularized tissue engineering. Biomed. Microdevices 2002, 4, $167-175$.

370. Song, J.W.; Gu, W.; Futai, N.; Warner, K.A.; Jacques, E.; Takayama, S. Computer-controlled microcirculatory support system for endothelial cell culture and shearing. Anal. Chem. 2005, 77, 3993-3999.

371. Huh, D.; Fujioka, H.; Tung, Y.C.; Futai, N.; Paine, R.; Grotberg, J.B.; Takayama, S. Acoustically detectable cellular-level lung injury induced by fluid mechanical stresses in microfluidic airway systems. Proc. Natl. Acad. Sci. USA 2007, 104, 18886-18891.

372. Antia, M.; Herricks, T.; Rathod, P.K. Microfluidic approaches to malaria pathogenesis. Cell. Microbiol. 2008, 10, 1968-1974.

373. Shelby, J.P.; White, J.; Ganesan, K.; Rathod, P.K.; Chiu, D.T. A microfluidic model for single-cell capillary obstruction by plasmodium falciparum-infected erythrocytes. Proc. Natl. Acad. Sci. USA 2003, 100, 14618.

374. Becker, H.; Gärtner, C. Polymer microfabrication methods for microfluidic analytical applications. Electrophoresis 2000, 21, 12-26.

375. Paulus, A.; Williams, S.J.; Sassi, A.P.; Kao, P.H.; Tan, H.; Hooper, H.H. Integrated capillary electrophoresis using glass and plastic chips for multiplexed DNA analysis. Proc. SPIE 1998, 351594-103.

376. Duffy, D.C.; McDonald, J.C.; Schueller, O.J.A.; Whitesides, G.M. Rapid prototyping of microfluidic systems in poly(dimethylsiloxane). Anal. Chem. 1998, 70, 4974-4984.

377. Chen, Y.H.; Chen, S.H. Analysis of DNA fragments by microchip electrophoresis fabricated on poly(methyl methacrylate) substrates using a wire-imprinting method. Electrophoresis 2000, 21, 165-170.

378. Shoffner, M.A.; Cheng, J.; Hvichia, G.E.; Kricka, L.J.; Wilding, P. Chip PCR. I. Surface passivation of microfabricated silicon-glass chips for PCR. Nucleic Acids Res. 1996, 24, 375-379.

379. Bélanger, M.C.; Marois, Y. Hemocompatibility, biocompatibility, inflammatory and in vivo studies of primary reference materials low-density polyethylene and polydimethylsiloxane: A review. J. Biomed. Mater. Res. 2001, 58, 467-477.

380. Charati, S.; Stern, S. Diffusion of gases in silicone polymers: Molecular dynamics simulations. Macromolecules 1998, 31, 5529-5535. 
381. Piruska, A.; Nikcevic, I.; Lee, S.H.; Ahn, C.; Heineman, W.R.; Limbach, P.A.; Seliskar, C.J. The autofluorescence of plastic materials and chips measured under laser irradiation. Lab chip 2005, $5,1348-1354$.

382. Toepke, M.W.; Beebe, D.J. PDMS absorption of small molecules and consequences in microfluidic applications. Lab Chip 2006, 6, 1484-1486.

383. Prieto, A.; Basauri, O.; Rodil, R.; Usobiaga, A.; Fernández, L.; Etxebarria, N.; Zuloaga, O. Stir-bar sorptive extraction: A view on method optimisation, novel applications, limitations and potential solutions. J. Chromatogr. A 2010, 1217, 2642-2666.

384. Paguirigan, A.L.; Beebe, D.J. From the cellular perspective: Exploring differences in the cellular baseline in macroscale and microfluidic cultures. Integr. Biol. 2009, 1, 182-195.

385. Van Midwoud, P.M.; Groothuis, G.M.M.; Merema, M.T.; Verpoorte, E. Microfluidic biochip for the perifusion of precision-cut rat liver slices for metabolism and toxicology studies. Biotechnol. Bioeng. 2010, 105, 184-194.

386. Amstein, C.F.; Hartman, P.A. Adaptation of plastic surfaces for tissue culture by glow discharge. J. Clin. Microbiol. 1975, 2, 46-54.

387. Makamba, H.; Kim, J.H.; Lim, K.; Park, N.; Hahn, J.H. Surface modification of poly(dimethylsiloxane) microchannels. Electrophoresis 2003, 24, 3607-3619.

388. Paguirigan, A.; Beebe, D. Gelatin based microfluidic devices for cell culture. Lab Chip 2006, 6, 407-413.

389. Zhang, X.; Haswell, S.J. Materials matter in microfluidic devices. MRS Bull. 2006, 31, 95-99.

390. Voskerician, G.; Shive, M.S.; Shawgo, R.S.; Recum, H.; Anderson, J.M.; Cima, M.J.; Langer, R. Biocompatibility and biofouling of MEMS drug delivery devices. Biomaterials 2003, 24, 1959-1967.

391. Van Midwoud, P.M. An alternative approach based on microfluidics to study drug metabolism and toxicity using liver and intestinal tissue. Ph.D. Dissertation. Faculty of Mathematics and Natural Sciences, University of Groningen, Groningen, The Netherlands, 2010.

392. Berthier, E.; Young, E.W.K.; Beebe, D. Engineers are from PDMS-land, biologists are from polystyrenia. Lab Chip 2012, 12, 1224-1237.

393. Lucas, J. Advances in plant disease and pest management. J. Agric. Sci. 2011, 149, 91-114.

394. Andersson, H.; van den Berg, A. Microfabrication and microfluidics for tissue engineering: State of the art and future opportunities. Lab Chip 2004, 4, 98-103.

395. Lutolf, M.P.; Gilbert, P.M.; Blau, H.M. Designing materials to direct stem-cell fate. Nature 2009, 462, 433-441.

396. Quantalife Homepage. Available online: http:/www.quantalife.com (accessed on 28 February 2012).

397. Scientific Application Resource Center. Available online: http://www.cellectricon.com/sites/ download/download_dynaflow.php (accessed on 28 February 2012).

398. Whitesides, G.M.; Stroock, A.D. Flexible methods for microfluidics. Phys. Today 2001, 54, $42-48$.

(C) 2012 by the authors; licensee MDPI, Basel, Switzerland. This article is an open access article distributed under the terms and conditions of the Creative Commons Attribution license (http://creativecommons.org/licenses/by/3.0/). 